Article

\title{
Transcriptome Sequencing Analysis of Birch (Betula platyphylla Sukaczev) under Low-Temperature Stress
}

\author{
Siyu Yan, Dawei Zhang, Song Chen $₫$ and Su Chen * \\ State Key Laboratory of Tree Genetics and Breeding, Northeast Forestry University, 26 Hexing Road, \\ Harbin 150040, China; yansiyu@nefu.edu.cn (S.Y.); darwinnefu@163.com (D.Z.); chensongnet@gmail.com (S.C.) \\ * Correspondence: chensu@nefu.edu.cn
}

Received: 23 July 2020; Accepted: 4 September 2020; Published: 7 September 2020

\begin{abstract}
Low temperature is one of the common abiotic stresses that adversely affect the growth and development of plants. In this study, we used RNA-Seq to identify low-temperature-responsive genes in birch and further analyzed the underlying molecular mechanism. Birch seedlings were treated by the low temperature $\left(6^{\circ} \mathrm{C}\right)$ for $0,1,1.5,2,2.5$, and $3 \mathrm{~h}$, respectively. A total of 3491 genes were differentially expressed after low-temperature stress. Gene Ontology (GO) and Kyoto Encyclopedia of Gene and Genomes (KEGG) functional enrichment analysis were performed for the differentially expressed genes (DEGs). GO analysis indicated that 3491 DEGs were distributed into 1002 categories, and these DEGs were enriched in "cell process", "metabolic process", and "stimulus response", under the "biological process" category; in "organelles" and "cell components", under the "cell component" category; and in "catalytic activity" and "adhesion", under the "molecular function" category. The KEGG enrichment indicated that 119 DEGs were involved in $\mathrm{Ca}^{2+}$ and plant hormone signal transduction; 205 DEGs were involved in secondary metabolic processes, such as lipid metabolism and phenylpropanoid biosynthesis pathway; and 20 DEGs were involved in photosynthesis. In addition, a total of 362 transcription factors (TFs) were differentially expressed under low-temperature stress, including AP2/ERF, C2H2, MYB-HB-like, WRKY, bHLH, WD40-like, and GRAS families. Gene Bpev01.c0480.g0081 (calmodulin-like CML38), Bpev01.c1074.g0005 (calmodulin-like CML25), Bpev01.c1074.g0001 (Calcium-binding EF-hand family protein), Bpev01.c2029.g0005 (calmodulin-like protein), Bpev01.c0154.g0008 (POD), Bpev01.c0015.g0143 (N-acetyl-1-glutamate synthase), and Bpev01.c0148.g0010 (branched chain amino acid transferase) were up-regulated at a high level, under low-temperature stress.
\end{abstract}

Keywords: Betula platyphylla; low-temperature stress; transcriptome; differentially expressed genes

\section{Introduction}

Low temperature is one of the adverse environmental stresses which affects the growth, development, and geographical distribution of plants. Plants have evolved sophisticated molecular mechanisms to deal with low-temperature stress [1], such as synthesis of cryoprotectants [2], scavenging of reactive oxygen species [3], and cold acclimation [1].

The cell membranes of plants first recognize the low-temperature signal and transmit it into intracellular parts [4]. Low-temperature stress changes the cell membrane from the liquid state to the gel state. This leads to a decreased fluidity, increased permeability, and changes in the structure of membrane proteins, which in turn cause metabolic disorders of plant cells [4]. For example, the $\mathrm{Ca}^{2+}$ channel on the cell membrane is opened under low temperature, and the $\mathrm{Ca}^{2+}$ concentration in the membrane is rapidly increased [5]. Calmodulin (CaM) transmits the $\mathrm{Ca}^{2+}$ flow signals and 
subsequently affects the expression of downstream genes and actives the MAPK pathway, as well [6]. At the same time, low-temperature stress destroys the membrane structure of plastid and affects photosynthetic electron transfer and energy metabolism [7,8]. The disorder of photosystem II (PSII) system leads to the accumulation of reactive oxygen species (ROS) in the plastid [9]. The excessive ROS will result in oxidative damage to biomolecules, including cell membranes, proteins, and DNA [6]. Meanwhile, low temperature will induce the accumulation of protective proteins, including heat-shock proteins (HSPs) [10], cold-regulatory proteins (COR), dehydrated proteins, cold-protected proteins [1], and various metabolites [11].

The key expression regulators of low-temperature-responsive genes in plants have been reported. C-repeat/dehydration-responsive element binding factors (CBFs) are the first identified transcription factors that regulate the expression of low-temperature-responsive genes in plants [12]. CBFs bind to the C-repeat/dehydration-responsive elements in promoters of cold-responsive genes [12,13]. Inducer of CBF expression 1 (ICE1) is an MYC-type bHLH transcription factor, which activates the expression of $C B F$ genes by directly binding to their promoters [14]. ICE1 can interact with SNOW1, which activates $C B F 3$ to adjust the tolerance of plants under low temperature [15]. A R2R3-MYB protein encoded by $M Y B 15$ can bind to promoters of $C B F$, to prevent their expression [16]. Ethylene insensitive 3 (EIN3) is a key transcription factor involved in transduction of ethylene signaling, which inhibits the expression of $C B F S$ and is a negative regulator of low-temperature resistance [17].

In recent years, with the rapid development of sequencing technology, a large number of experiments have been carried out to study the mechanism of plants under low temperature, using high-throughput sequencing [18-23]. The RNA-Seq studies found that genes related to transcription factors [24], $\mathrm{Ca}^{2+}$ signaling [25], plant-hormone signaling [26], phenylalanine biosynthesis [27], starch and sucrose metabolism [28], and protein metabolism pathways may play important roles in the response to low-temperature stress. Birch is one of the most common tree species in the northern hemisphere [29]. In this study, we used RNA-Seq to identify the low-temperature-responsive genes in birch within a short time frame and analyze the responsive mechanism of birch exposed to low-temperature stress.

\section{Materials and Methods}

\subsection{Plant-Material Treatment and RNA Isolation}

Two-month-old birch (Betula platyphylla Sukaczev) were grown and maintained in the greenhouse, under a $16 \mathrm{~h} \mathrm{light} / 8 \mathrm{~h}$ dark photoperiod, at $25^{\circ} \mathrm{C}$, at Northeast Forestry University. For low-temperature stress treatment, plant materials were transferred to $6^{\circ} \mathrm{C}$ and harvested after $1,1.5,2,2.5$, or $3 \mathrm{~h}$ treatment, for RNA sequencing. Plants grown at normal condition $(0 \mathrm{~h}$ time point $)$ were used as controls. Two biological replicates were performed for each time point, except for $1.5 \mathrm{~h}$, and each biological replicate included at least ten individual plants. For $1.5 \mathrm{~h}$, three cDNA libraries were qualified for RNA sequencing. Before RNA isolation, all the samples were cleaned with sterile water. Total RNAs of all the samples were extracted, using the CTAB [30] method. The quality and concentration of RNA were examined by NanoDrop 2000. The integrity of the RNA samples was examined with an Agilent 2100. The cDNA library was constructed at Beijing Biomarker Technology and sequenced on Illumina platform, with a 150 bp paired-end read length. The transcriptome data obtained in this study were submitted to the NCBI SRA database which is a database for storing the original data of second-generation sequencing. (NCBI accession number: PRJNA532995).

\subsection{Transcriptome Analysis}

Clean reads were obtained by filtration of low-quality reads, using fastp [31]. All the clean reads were mapped to the birch genome (v1.4c) [32], using HISAT2, with default parameters [33]. Differentially expressed genes (DEGs) between the control group and each treatment group were identified, using DEG discovery pipeline HTSFilter [34] and edgeR, with thresholds of false discovery rate (FDR) $<0.05$ 
and $\mid \log 2$ of fold change| $>1$ [35]. The genes expression abundance was normalized by FPKM (number of fragments per kilobase of transcript per million map reads) method. The hypergeometric test was used for GO (Gene Ontology) enrichment analysis. The Bonferroni method was used to correct the $p$-value. KOBAS2.0 [36] software was used to detect the significantly enriched Kyoto Encyclopedia of Gene and Genomes (KEGG) pathways. BLASTx $\left(\right.$ E-value $\left.<1.0 \times 10^{-5}\right)$ [37] was used for functional annotation of birch genome, using RefSeq non-redundant proteins (NR) [38], Swiss-Prot [39], and Kyoto Encyclopedia of Genes and Genomes (KEGG) [40] as databases. The transcription factors (TFs) were annotated, using a plant TFs database (http://plntfdb.bio.uni-potsdam.de/v3.0/).

\subsection{Quantitative RT-PCR Analysis}

The HiFiScript cDNA Synthesis Kit was used to reverse transcribe the extracted RNA samples for fluorescence quantitative detection [41]. Applied Biosystems 7500 Real-Time PCR System was used to perform qRT-PCR. A total of 12 DEGs were selected to validate the RNA-Seq results. The $18 \mathrm{~S}$ of birch was used as an internal reference gene. All the primers were designed by using primer 3 software. The primer sequences are listed in Table A1.

\section{Results}

\subsection{Statistics of Transcriptome Sequencing Data}

A time series RNA-Seq experiment was carried out to reveal the transcriptomic response of birch to low-temperature stress, within a short time. Young leaves of birch exposed to $4{ }^{\circ} \mathrm{C}$ for $0,1,1.5,2,2.5$, and $3 \mathrm{~h}$ were harvested for RNA sequencing on Illumina platform. After the filtration of low-quality reads, an average of $25,120,872$ reads was obtained for each sample. The detailed information of the sequencing of reads is shown in Table A2. The results indicated that the obtained sequencing reads are qualified for subsequent analysis.

\subsection{Analysis of Differentially Expressed Genes (DEGs)}

In order to obtain low-temperature-responsive genes in birch, we first used HISAT2 [33] to align the sequencing reads to the birch reference genome. DEGs in the treatment groups relative to the control group were identified by using edgeR [42], with thresholds of FDR $\leq 0.05$ and absolute value of $\log 2$ (fold-change) $>1$. The results showed that 3197 (1656 up-regulated and 1541 down-regulated), 881 (494 up-regulated and 387 down-regulated), 79 (67 up-regulated and 12 down-regulated), 859 (470 up-regulated and 389 down-regulated), and 451 (378 up-regulated and 73 genes down-regulated) genes were differentially expressed after 1, 1.5, 2, 2.5, and $3 \mathrm{~h}$ exposure to low temperature, respectively (Table 1). In total, 3491 genes were differentially expressed in at least one time point.

Table 1. Differentially expressed genes (DEGs) under different low-temperature stress time points.

\begin{tabular}{ccccccc}
\hline DEGs & $\mathbf{1} \mathbf{h}$ & $\mathbf{1 . 5} \mathbf{h}$ & $\mathbf{2} \mathbf{h}$ & $\mathbf{2 . 5} \mathbf{h}$ & $\mathbf{3} \mathbf{h}$ & Total \\
\hline All_DEGs & 3197 & 881 & 79 & 859 & 451 & 3491 \\
Up-regulated & 1656 & 494 & 67 & 470 & 378 & 1764 \\
Down-regulated & 1541 & 387 & 12 & 389 & 73 & 1727 \\
\hline
\end{tabular}

\subsection{Gene Ontology (GO) and KEGG Enrichment of the DEGs}

In order to reveal the biological processes underlying the DEGs, we performed GO enrichment analysis for the 3491 DEGs. Using FDR values $\leq 0.05$ as a threshold, a total of 1002 GOs of cellular component, molecular function, and biological process were identified as enriched GO terms (Figure 1). 


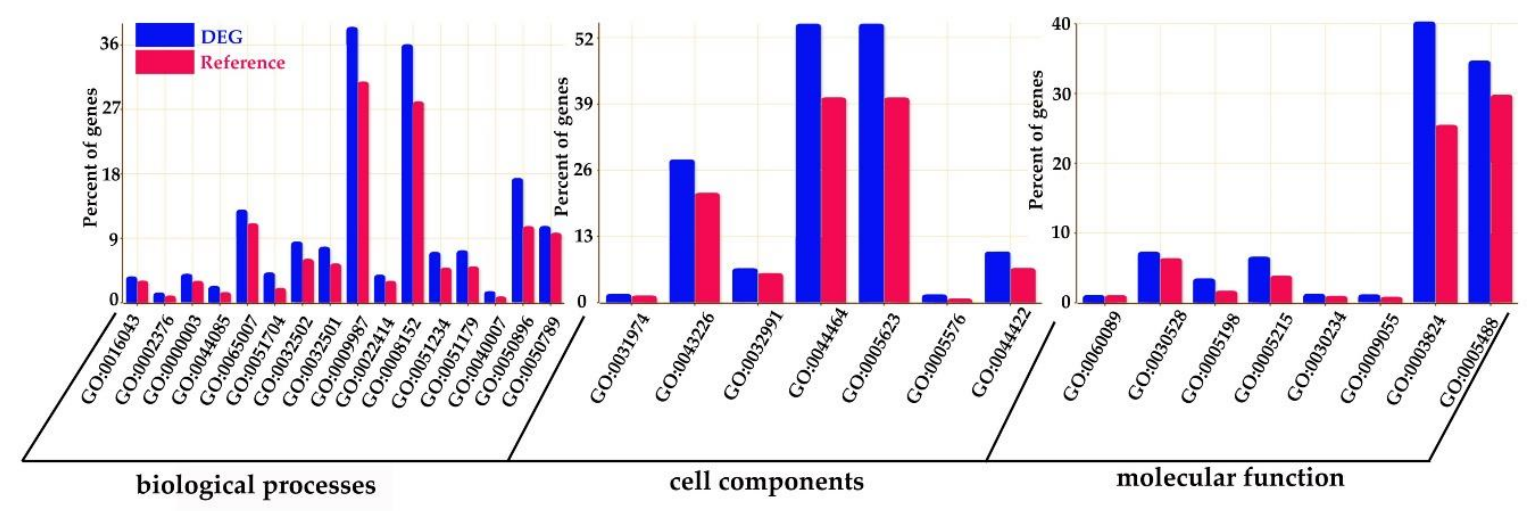

Figure 1. Function annotation of the DEGs in Gene Ontology. The $x$-axis is the Gene Ontology (GO) terms, and the $y$-axis is the percent of genes in each GO term. The blue columns represent the percentage of DEGs in each GO term, and the red columns represent the percentage of reference in each GO term. This figure shows the enrichment of DEGs and reference.

In the category of biological process, a total of 610 GOs were enriched. GOs such as GO:0009987 (cell process), GO:0008152 (metabolic process), and GO:0050896 (response to stimulus) were significantly enriched (Figure 1). The results indicate that genes involved in these biological processes may play an important role in the response to low-temperature stress. Biological processes such as GO:0008152 (metabolic process), GO:0044237 (cell metabolic process), GO:0006793 (phosphorus metabolic process), GO:0006796 (phosphate metabolic process), GO:0016310 (phosphorylation), and GO:0006468 (protein Amino acid phosphorylation) were enriched as well (Figure A1). In the category of cell components, a total of 131 GOs were enriched. GOs including GO:0044464 (cell component) and GO:0043226 (organelle) were enriched (Figures 1 and A2). In the category of molecular function, a total of 261 GOs were enriched. Among them, GOs such as GO:0003824 (catalytic activity) and GO:0005488 (binding activity) were enriched (Figure 1). In addition, GO:0016740 (transferase activity), GO:0016772 (transferase activity, transfer phosphorus-containing groups), GO:0016301 (kinase activity), GO:0004672 (protein kinase activity), and GO:0004674 (protein serine/threonine kinase activity) were significantly enriched (Figure A3).

KEGG pathway enrichment analysis of the DEGs was performed by KOBAS 3.0. All DEGs were allocated to 121 metabolic pathways, 47 of which were significantly enriched $(p \leq 0.05)$ (Table A3). The results indicated that the DEGs were mainly enriched in metabolic pathways, biosynthesis of secondary metabolites, ribosomes, amino acid biosynthesis, carbon metabolism, phenylpropanoid biosynthesis, plant hormone signal transduction, plant pathogenic bacteria interaction, and starch and sucrose metabolism. These enriched pathways may play important roles in the process of birch in response to low-temperature stress (Figure 2). 


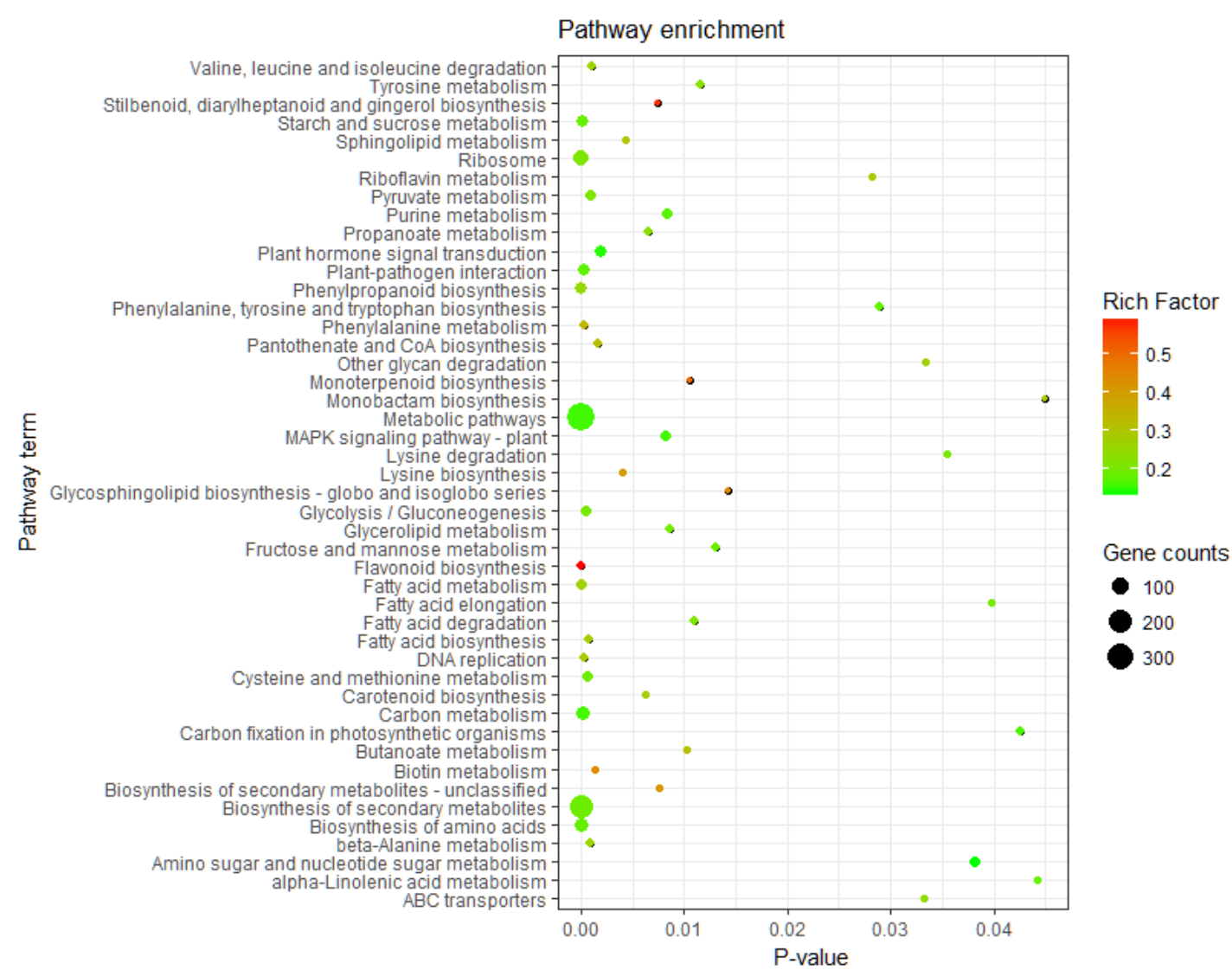

Figure 2. Pathway assignment of DEGs based on Kyoto Encyclopedia of Gene and Genomes (KEGG).

\subsection{Analysis of DEGs Related to Calcium Signal Transduction Pathway}

The calcium signal transduction pathway plays a vital role in perceiving the low-temperature stress of plants. In this study, a total of 50 DEGs related to calcium signal transduction were identified, of which 40 were up-regulated. The up-regulated genes include four calcium-dependent protein kinase (CDPK) genes, nine calmodulin-like protein (CML) genes, three calmodulin-binding protein-like genes, and four CBL-interacting protein kinase (CIPK) genes. The expression levels of these genes were significantly up-regulated after low-temperature treatment (Table A4). In addition, six EF-hand calcium-binding proteins (calcium-binding EF-hand family protein) were differentially expressed, of which five were up-regulated. Of the eight calcium-dependent lipid-binding (CaLB domain) family proteins, seven were up-regulated. All the results indicated that genes in the calcium signal transduction pathway of birch respond positively to low-temperature stress.

\subsection{Analysis of Hormone and Signal Transduction Pathways-Related DEGs}

Under low-temperature stress, the expression of genes related to plant hormone biosynthesis or signal transduction were significantly affected (Table A5). According to the KEGG results, we found that 23 genes related to abscisic acid (ABA) biosynthesis were differentially expressed, of which 15 were up-regulated. Bpev01.c0268.g0003, encoding a 9-cis-epoxy carotenoid dioxygenase, which is an important enzyme in ABA biosynthesis, was up-regulated under low-temperature stress. In addition, we identified 15 DEGs encoding protein phosphatase 2C (PP2C), and 11 of them were up-regulated. Studies have shown that PP2C in plants may play a role in the activation of signaling pathways by environmental stresses, such as cold damage [43]. An ABA 8'-hydroxylase encoding gene (Bpev01.c0870.g0008) was up-regulated by 4.01 times. Bpev01.c0015.g0010, encoding ABA1, which converts zeaxanthin to antheraxanthin and violaxanthin through the epoxidation, was up-regulated under the low-temperature stress. 
Most ethylene-signal-related genes in birch were up-regulated under low-temperature stress. We identified a total of 12 ethylene-signal-transduction-related genes, including one ethylene synthase encoding gene (Bpev01.c0299.g0032), one ethylene insensitive 3 gene (EIN3, Bper01.c0523.g0001), and ten ethylene response transcription factors (BpERFs). In addition, five DEGs related to the gibberellin signaling pathway were identified. Table A5 shows that the differential expression of the five genes (Bpev01.c0118.g0033, Bpev01.c0094.g0034, Bpev01.c1673.g0004, Bpev01.c0411.g0004, and Bpev01.c1170.g0013) may cause a decrease in gibberellin content.

\subsection{Identification of DEGs Related to Starch and Sucrose Metabolic Pathways}

When exposed to low-temperature stress, many metabolic processes of plants were affected. The enrichment analysis of GO and KEGG indicated that genes related to metabolism and biosynthesis were significantly differentially expressed. A total of 29 DEGs related to the "starch and sucrose metabolism" (Ko00500) pathway were identified, of which 15 were up-regulated and 14 were down-regulated (Table A6). These DEGs include five glucosidase genes, of which four were up-regulated and two up-regulated amylase genes. The pfkB-like carbohydrate kinase genes Bpev01.c0080.g0100 and Bpev01.c0762.g0008 were up-regulated by 4.58 times and down-regulated by 1.29 times, respectively. However, the reason for this remains to be further studied. The eight glycosyl hydrolase genes were significantly down-regulated, and one DEGs encoded to trehalose-6-phosphate synthase were up-regulated. Let us notice that the sugar contents in plants under low-temperature stress may increase, in this case.

\subsection{Identification of DEGs Related to Lipid Metabolism}

A total of 109 DEGs related to lipid metabolism were identified in this study, most of which were related to oxidation of lipids, biosynthesis, and metabolic processes of lipids and fatty acids (Table A7). The Bpev01.c0190.g0079 gene encodes UDP-sulfoquinolone and participates in the biosynthesis of sulfide lipid, the Bper01.c1135.g0005 gene encodes a long-chain acyl-CoA synthetase, and the Bpev01.c0364.g0019 gene encodes monogalactosyldiacylglycerol (MGDG) synthase; and these three genes were up-regulated in birch, under low-temperature stress. In addition, a total of 20 GDSL-like esterases/lipases were identified, including one up-regulated and 19 down-regulated DEGs, and the most expression level for down-regulated was up to 4.92 times of the control group. GDSL lipase is a multifunctional family of hydrolases that can hydrolyze a variety of substrates, such as thioesters, aryl esters, phospholipids, and amino acids [43]. In addition, the Bpev01.c0569.g0008 gene encodes a plant ene desaturase, and it was also up-regulated. A total of three genes (Bper01.c1627.g0007, Bpev01.c2716.g0001, and Bpev01.c2716.g0001) encode terpene synthase and were down-regulated.

\subsection{Identification of DEGs Related to Amino Acid Biosynthetic Pathway}

Low-temperature response of amino acids to plants is also important, such as the "amino acid biosynthesis" pathway (ko01230). A total of 40 DEGs were found in this pathway, including 17 up-regulated, such as the gene Bpev01.c0015.g0143, which encodes the N-acetyl-l-glutamic acid synthase and was up-regulated by 9.63 times (Table A8). In addition, six gene were also up-regulated, including one encoding pyridoxal-5' -phosphate-dependent enzyme (Bpev01.c0112.g0007), two encoding aldolase (Bpev01.c0511.g0007 and Bpev01.c0115.g0053), one encoding ATP phosphotransferase (Bpev01.c0274.g0001), one encoding branch-chain amino acid transferase (Bpev01.c0148.g0010), and one encoding cysteine synthase (Bpev01.c0137.g0017) (Table A8). Gene Bpev01.c3196.g0001 and Bpev01.c0652.g0026 were down-regulated which encodes the dihydropyridine carboxylic acid reductase and shikimate kinase, respectively (Table A8).

\subsection{Identification of DEGs Related to Photosynthesis}

A total of 21 DEGs related to photosynthesis were identified, including 13 up-regulated and eight down-regulated (Table A9). Among this, genes (Bpev01.c1891.g0002 and Bper01.c1891.g0006) 
that encoded photosystem II reaction centers A and C were up-regulated by 4.02 and 3.49 times, respectively. The gene (Bpev01.c1891.g0007) encoded photosystem I PsaA/PsaB protein was up-regulated by 3.05 times. The gene (Bpev01.c0154.g0066) encoded ferritin 1 was up-regulated by 4.19 times. Genes encoded phosphoenolpyruvate carboxykinase (Bpev01.c1286.g0001), photosystem II subunit R (Bpev01.c1275.g0002), and chloroplast-sensing kinase (Bpev01.c0038.g0100) were also up-regulated. Six genes were down-regulated, including one encoding chlorophyll $\mathrm{A} / \mathrm{B}$ binding protein (Bper01.c0615.g0010), one encoding ferredoxin 3 (Bper01.c0536.g0012), one encoding tubulin FtsZ (Bpev01.c0327.g0054), one encoding membrane localization protein MinD (Bpev01.c0298. g0026), and two encoding the PsbP family proteins of the photosystem II reaction center (Bpev01.c0118.g0021 and Bpev01.c0142.g0012).

\subsection{Transcription Factors Involved in Low-Temperature Response}

Transcription factors (TFs) play important roles in transcriptional regulation of plants under abiotic stress. TFs are also the core nodes that initiate downstream genes. In this study, a total of 362 TFs were found to be classified into 58 families, including the AP2/EREBP, C2H2, MYB-HB-like, WRKY, bHLH, bZIP, WD40-like, and GRAS families (Table 2). In the $1 \mathrm{~h}$ sample, $276 \mathrm{TFs}$ that were classified into 51 TFs families were differentially expressed; among all the families, the $\mathrm{C} 2 \mathrm{H} 2$ family contained the maximum DEGs, adding up to 53 TFs. It was followed by the AP2-EREBP family (29 TFs), MYB-HB-like families (21 TFs), NAM families (18 TFs), and WD40-like families (16 TFs). In the $1.5 \mathrm{~h}$ sample, $112 \mathrm{TFs}$ belonged to $31 \mathrm{TFs}$ families, including the AP2-EREBP family (25 TFs), Hap3/NF-YB family (13 TFs), and C2H2 families (11 TFs), MYB-HB-like family (7 TFs), Znf-B family (6 TFs), and NAM family (5 TFs). In the $2 \mathrm{~h}$ sample, $25 \mathrm{TFs}$ belonged to seven TFs families; among them, the AP2-EREBP family has $14 \mathrm{TFs}$, the $\mathrm{C} 2 \mathrm{H} 2$ family has six TFs, and the $\mathrm{C} 3 \mathrm{H}, \mathrm{PHD}, \mathrm{RAV}$, AUX-IAA, and Bromo-domain families have one TF, respectively. In the $2.5 \mathrm{~h}$ sample, $120 \mathrm{TFs}$ belonged to 35 TFs families, including 24 AP2-EREBP, 16 C2H2, 10 Hap3/NF-YB, seven MYB-HB-like, six NAM, five GRAS, and five WRKY transcription factor genes. In the $3 \mathrm{~h}$ sample, $78 \mathrm{TFs}$ belonged to $20 \mathrm{TFs}$ families, including 24 AP2-EREBP, 14 C2H2, six MYB-HB-like, five WRKY, four Znf-B, three GRAS, and three NAM transcription factor genes.

Table 2. Differentially expressed transcription factors (TFs) under different low-temperature stress time points.

\begin{tabular}{ccccccc}
\hline TF Family & Total & $\mathbf{1} \mathbf{h}$ & $\mathbf{1 . 5} \mathbf{h}$ & $\mathbf{2} \mathbf{h}$ & $\mathbf{2 . 5} \mathbf{h}$ & $\mathbf{3} \mathbf{h}$ \\
\hline C2H2 & 58 & 53 & 11 & 6 & 16 & 14 \\
AP2-EREBP & 42 & 29 & 25 & 14 & 24 & 24 \\
MYB-HB-like & 27 & 21 & 7 & 0 & 7 & 6 \\
NAM & 20 & 18 & 5 & 0 & 6 & 3 \\
WD40-like & 20 & 16 & 5 & 0 & 4 & 0 \\
WRKY & 16 & 15 & 2 & 0 & 5 & 5 \\
bHLH & 15 & 12 & 1 & 0 & 2 & 1 \\
Hap3/NF-YB & 15 & 1 & 13 & 0 & 10 & 0 \\
PHD & 14 & 10 & 2 & 1 & 0 & 0 \\
Homobox-WOX & 10 & 10 & 3 & 0 & 1 & 2 \\
bZIP & 8 & 8 & 0 & 0 & 0 & 0 \\
GRAS & 8 & 7 & 4 & 0 & 5 & 3 \\
Znf-B & 7 & 5 & 6 & 0 & 4 & 4 \\
C2C2-Dof & 6 & 4 & 1 & 0 & 2 & 2 \\
C2C2-GATA & 6 & 4 & 1 & 0 & 2 & 2 \\
BTB-POZ & 5 & 4 & 1 & 0 & 2 & 0 \\
C3H & 5 & 4 & 2 & 1 & 3 & 2 \\
C3H-WRC/GRF & 5 & 2 & 3 & 0 & 3 & 0 \\
HSF-type-DNA-binding & 5 & 4 & 3 & 0 & 3 & 2 \\
A20-like & 4 & 4 & 1 & 0 & 2 & 0 \\
HD-ZIP & 4 & 2 & 2 & 0 & 2 & 1 \\
\hline
\end{tabular}


Although the C2H2TFs family had the most DEGs (53) at the $1 \mathrm{~h}$ sample, the AP2/ERF family contained the most DEGs at the other four samples. Interestingly, 13 AP2/ERF family genes were up-regulated in all samples, which are the most among all the TFs families (Table A10).

\subsection{Validation of RNA-Seq Based DEGs Results by qRT-PCR}

To verify the accuracy of the RNA-Seq data, we analyzed the transcript abundance of the 12 randomly selected DEGs, using qRT-PCR. All 12 up-regulated genes were significantly induced by the low-temperature stress, which was consistent with the results of RNA-Seq data (Figures 3 and 4). This result confirmed the reliability of RNA-Seq analysis.
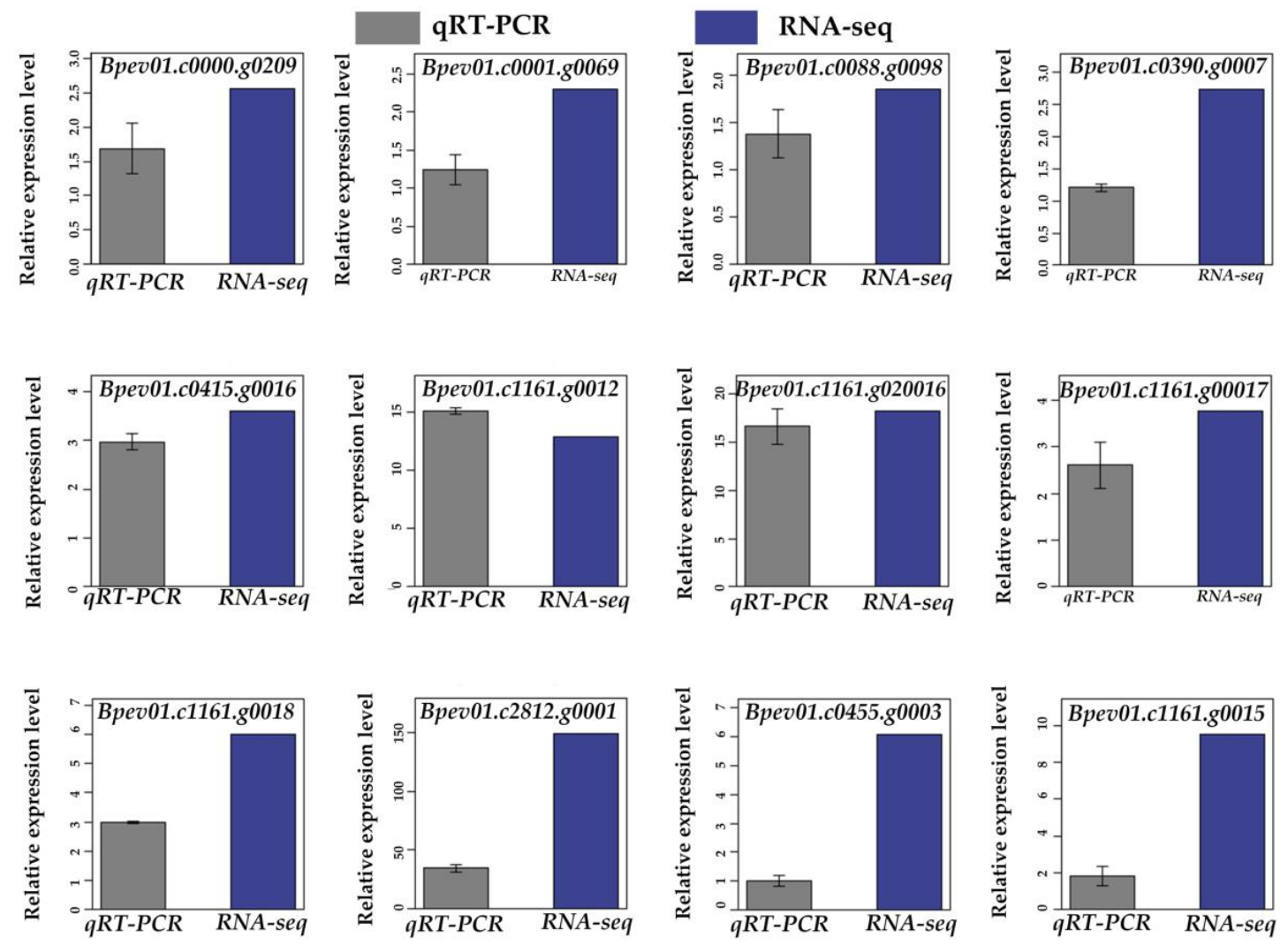

Figure 3. Validation of the RNA-Seq results by qRT-PCR. A total of 12 DEGs were selected for the validation.

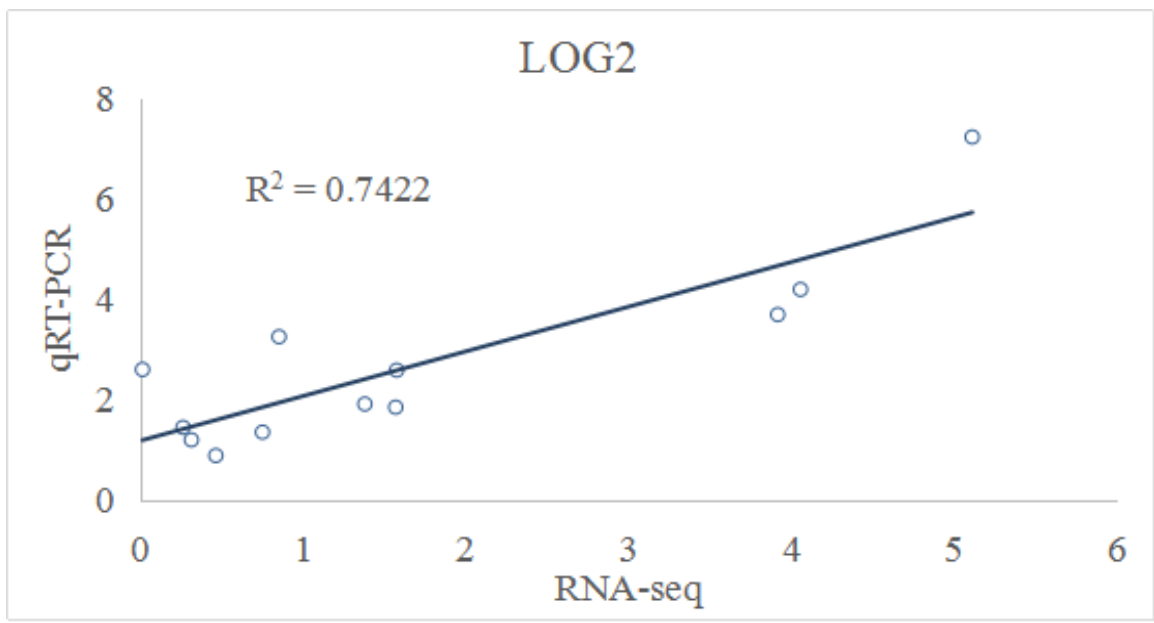

Figure 4. Expression analysis of selected DEGs, using qRT-PCR. 


\section{Discussion}

The research led us to find that, in the biological process under low temperatures, DEGs were abundantly enriched in the protein phosphorylation pathway downstream of the metabolic pathway. Protein phosphorylation pathways can regulate and control protein activity and function in order to better play the role of protein under low-temperature stress.

\section{1. $\mathrm{Ca2}{ }^{+}$Signal Transduction under Low Temperature}

$\mathrm{Ca}^{2+}$ is the second messenger in plant cells which plays an important role in many signaling pathways. Fluctuations in calcium levels can be monitored by calcium sensor proteins, including calmodulin-like (CML), calcineurin B-like protein (CBL), and calcium-dependent protein kinases (CDPK); they transmit signals and trigger downstream reactions [44]. In this study, 50 DEGs related to calcium signal transduction pathways were identified, including nine CMLs, four CDPKs, three CML binding protein, and four CBL interacting protein kinases (CIPK). Compared with the control group, they were all increased. In addition, six EF-hand proteins were identified, including five that were up-regulated. In plants, EF-hand proteins include calmodulin ( $\mathrm{CaMs}), \mathrm{Ca}^{2+}$-dependent protein kinases (CDPKs), and calmodulin B-like protein (CBL); they are all $\mathrm{Ca}^{2+}$ receptors. Among them, CaMs and CMLs are important, and they have an important role in sensing and transmission of $\mathrm{Ca}^{2+}$ signals [45]. CIPK7 may be combined with the CBL, and thus participate in the low-temperature response of plants [46]. This study found that four CDPK, nine CMLs, and four CIPK protein kinases were up-regulated, indicating that $\mathrm{Ca}^{2+}$-mediated signaling pathways play an important role in the response of low-temperature stress in birch.

\subsection{Plant Hormone-Dependent Pathways under Low Temperature}

ABA is considered to be a necessary messenger for plants to adapt to abiotic stress. Studies have shown that, under abiotic stress, genes involved in ABA synthesis and signal transduction are mostly differentially expressed, such as homologous genes of PYR/PYL and homologous genes of PP2C [47,48]. This study found that, under low-temperature stress, birch has 23 DEGs related to the ABA pathway, including 15 up-regulated and eight down-regulated. The birch Bpev01.c0294.g0006 and Bpev01.c0268.g0003 genes encode 9-cis-epoxy carotenoid dioxygenase (NCED), which is a key enzyme in ABA biosynthesis, up-regulated 3.66 times and 1.44 times under low-temperature stress, respectively. This indicates that ABA content may increase in birch, under low-temperature stress. Fifteen DEGs encoded protein phosphatase 2C (PP2C) were also detected, and among them, 11 were up-regulated and four down-regulated. $\mathrm{PP} 2 \mathrm{C}$ is also a key component of the ABA signaling pathway. These DEGs indicate that ABA-mediated signal transduction is involved in the birch response to low-temperature stress.

Many researches have proved that ethylene may play a different role in different plants under low-temperature stress. For example, it plays an active role in rice, tomato and Arabidopsis, but it plays a negative regulatory role in safflower and magnolia [49]. Studies have shown that EIN3 can regulate the expression of ERF TFs [50], and EFE is a very important enzyme in the process of ethylene production [51,52]. In our study, a total of 12 DEGs related to ethylene signal transduction were identified, including 1 EFE (Bpev01.c0299.g0032) and 1 EIN3 (Bpev01.c0523.g0001) and 10 ERF1, 2, 3, 5. Interestingly, these DEGs were up-regulated and indicating that ethylene plays an positive role in the response of birch under low-temperature stress.

In addition, this study also detected 4, 5, and 11 DEGs related to the jasmonic acid signaling pathway, the gibberellin signaling pathway, and the salicylic acid signaling pathway, respectively. It indicated that these hormones may also be involved in the response of birch to low-temperature stress. 


\subsection{Low-Temperature Stress Signal Induces Cell Protection Process}

When plants are subjected to low temperatures, plant cells will quickly accumulate compatible solutes (osmoprotectants), including sugar, amino acids, and fatty acids. These osmoprotectants can help re-establish the cell's osmotic balance and thus play a key role in protecting organelles, proteins, and membranes. Some studies have confirmed that sugars can be used as ROS scavengers to protect plants from oxidative damage caused by low temperature [53]. In this study, 30 DEGs were found in the starch and sucrose metabolic pathways, including eight genes encoded in the glycosyl hydrolases which were significantly down-regulated. It may be indicated that decomposition of sugar was reduced under low-temperature stress. Moreover, the gene encoded of trehalose-6-phosphate synthase was up-regulated, and a study in 2011 had confirmed that the accumulation of trehalose can be used for oxidative detoxification under abiotic stress [54]. In addition, a total of three genes that encoded amylase were up-regulated; we speculate that birch resists low temperature by breaking down starch into soluble sugars, under low-temperature stress.

In this study, a total of 109 DEGs related to lipid metabolism were identified in birch, under low temperature. Among them, the gene Bpev01.c0190.g0079 encodes UDP-sulfoquinolone and is involved in the biosynthesis of sulfurized lipids, the gene Bpev01.c1135.g0005 encodes long acyl-CoA synthetase, and the gene Bpev01.c0364.g0019 encodes monogalactoside diacylglycerol synthase. These three genes were up-regulated and involved in the synthesis of lipids.

According to reports, amino acids are important osmotic protectants, and their accumulation is positively correlated with cold resistance [55]. In this study, genes encoded N-acetyl-1-glutamate synthase, L-lysine- $\alpha$-aminotransferase, branched-chain amino acid transferase, aldolase, and cysteine synthase were up-regulated. These enzymes were involved in amino acid synthesis, and thus we speculated that the content of amino acids might increase under low-temperature stress. In addition, a total of eight DEGs which encoded phenylalanine ammonia-lyase (PAL) and peroxidase were all significantly up-regulated. PAL is one of the most relevant enzymes in the biosynthetic pathway of phenylpropane [50], peroxidase can oxidize phenols and remove reactive oxygen [51]. Based on this, we believe that the synthesis of phenylpropane and peroxidase was increased under low-temperature stress.

\subsection{Transcription Factors Involved in Response to Cold Stress}

The regulation of TFs is a key part of plant response to low-temperature stress, and TFs can regulate their expression through interaction with stress genes. Many TFs families are connected with adversity stress, such as AP2/EREBP, bHLH, WRKY, MYB, NAC, MYC, HSF, bZIP, and GRAS families [56-58]. In this study, a total of 362 TFs had differentially expressed and clustered into 58 TFs families, under low-temperature stress; among them, the AP2/ERF family had the most DEGs. It is worth noting that a total of 13 genes in the AP2/ERF family were up-regulated in all the samples treated at low-temperature, which was much higher than other TFs families. This indicates that the AP2/ERF family plays a more important role in birch response to low-temperature stress. In addition, we also noticed that low temperatures lead to TFs having differential expression in the C2H2, MYB-HB-like, WRKY, bHLH, bZIP, WD40-like, and GRAS families. Based on this, we speculated that these TFs families also play an indispensable role in response to birch cold stress.

\subsection{Effects of Low-Temperature Stress on Photosynthesis}

Chloroplasts are distinct organelles in plant cells and provide most of the energy through photosynthesis. When plants are under low-temperature stress, the expression of genes related to chlorophyll biosynthesis is suppressed, and it will cause the destruction of the thylakoid function and the inhibition of photosynthesis. In this study, we identified a total of 21 DEGs (13 up-regulated and eight down-regulated) that were related to photosynthesis; among them, genes encoded chlorophyll $\mathrm{A} / \mathrm{B}$ binding protein, photosystem II reaction-center (PsbP) protein, ferredoxin 3, and diaphragm locating 
protein (MinD) were all down-regulated. Chlorophyll a/b binding protein and chlorophyll-protein complexes are mainly responsible for collecting light energy and transferring it into the photochemical reaction center. Foreign protein PsbP of the photosystem II is necessary for oxygen metabolism in photosynthesis. [52]. Ferredoxin of the photosystem I regulates the direction of electron transfer in photosynthetic electron transport, to affect plant photosynthesis [59], and the tubulin FtsZ is the key protein of chloroplast division [60,61]. The genes that encoded these proteins were down-regulated, and we can speculate that low-temperature stress inhibits the processes of light energy conversion and chloroplast division in birch photosynthesis, to a certain extent. However, we noticed that the genes that encoded the ferredoxin 1, the PsaA/PsaB protein, and the phosphoenolpyruvate carboxylase (PEPC) were all significantly up-regulated. The differential expression of these genes indicated that, although the photosynthesis of birch was inhibited under low-temperature stress, it could also be promoted by increasing the expression of some genes. We identified 30 genes that were significantly up-regulated under low-temperature stress, which were related to calcium signal pathway, plant hormone, starch and sucrose metabolism, amino acids biosynthesis, and photosynthesis, respectively (Table 3).

Table 3. Thirty significantly up-regulated DEGs of birch under low-temperature stress.

\begin{tabular}{|c|c|c|c|}
\hline Gene_ID & Time & $\operatorname{logFC}$ & Function \\
\hline \multicolumn{4}{|c|}{ Calcium signal pathway } \\
\hline Bpev01.c1074.g0005 & $2.5 \mathrm{~h}$ & 4.66 & Calmodulin-like, CML25 \\
\hline Bpev01.c0480.g0081 & $2 \mathrm{~h}$ & 4.57 & Calmodulin-like, CML38 \\
\hline Bpev01.c1074.g0006 & $3 \mathrm{~h}$ & 4.48 & Calcium-binding EF-hand family protein \\
\hline Bpev01.c1074.g0007 & $2.5 \mathrm{~h}$ & 3.94 & Calcium-binding EF-hand family protein \\
\hline Bpev01.c0088.g0124 & $1 \mathrm{~h}$ & 3.79 & $\mathrm{Ca}^{+}{ }^{+}$-dependent modulator of ICR1, CMI1 \\
\hline \multicolumn{4}{|c|}{ Hormone } \\
\hline Bpev01.c0343.g0021 & $1 \mathrm{~h}$ & 7.67 & Pathogenesis-related gene 1 \\
\hline Bpev01.c1161.g0016 & $2.5 \mathrm{~h}$ & 5.23 & Ethylene responsive element binding factor 5 \\
\hline Bpev01.c1161.g0012 & $2.5 \mathrm{~h}$ & 4.68 & Ethylene responsive element binding factor 5 \\
\hline Bpev01.c1161.g0014 & $2.5 \mathrm{~h}$ & 4.63 & Ethylene responsive element binding factor 5 \\
\hline Bpev01.c0870.g0008 & $2.5 \mathrm{~h}$ & 4.01 & ABA 8'-hydroxylase, polypeptide 1 \\
\hline \multicolumn{4}{|c|}{ Starch and sucrose metabolism } \\
\hline Bpev01.c0162.g0017 & $1 \mathrm{~h}$ & 5.07 & Beta-glucosidase 45 \\
\hline Bpev01.c0080.g0100 & $1 \mathrm{~h}$ & 4.58 & PfkB-like carbohydrate kinase family protein \\
\hline Bpev01.c0283.g0018 & $1 \mathrm{~h}$ & 3.15 & Beta-amylase 5 \\
\hline Bpev01.c0092.g0014 & $1 \mathrm{~h}$ & 2.77 & Beta glucosidase 41 \\
\hline Bpev01.c0275.g0002 & $1 \mathrm{~h}$ & 2.59 & Sucrose-phosphate synthase family protein \\
\hline \multicolumn{4}{|c|}{ Amino acids biosynthesis } \\
\hline Bpev01.c0015.g0143 & $1 \mathrm{~h}$ & 9.63 & N-acetyl-l-glutamate synthase 2 \\
\hline Bpev01.c0112.g0007 & $3 \mathrm{~h}$ & 8.44 & $\begin{array}{l}\text { Pyridoxal-5' - phosphate-dependent enzyme } \\
\text { family protein }\end{array}$ \\
\hline Bpev01.c0511.g0007 & $3 \mathrm{~h}$ & 7.44 & Aldolase superfamily protein \\
\hline Bpev01.c0148.g0010 & $1 \mathrm{~h}$ & 4.59 & Branched-chain amino acid transaminase 2 \\
\hline Bpev01.c0115.g0053 & $1 \mathrm{~h}$ & 4.03 & Aldolase superfamily protein \\
\hline \multicolumn{4}{|c|}{ Photosynthesis } \\
\hline Bpev01.c0154.g0066 & $1.5 \mathrm{~h}$ & 4.19 & Ferritin 1 \\
\hline Bpev01.c1891.g0002 & $1.5 \mathrm{~h}$ & 4.02 & Photosystem II reaction center protein A \\
\hline Bpev01.c1891.g0006 & $1.5 \mathrm{~h}$ & 3.49 & Photosystem II reaction center protein C \\
\hline Bpev01.c1891.g0007 & $1.5 \mathrm{~h}$ & 3.05 & Photosystem I, PsaA/PsaB protein \\
\hline Bpev01.c0245.g0079 & $1 \mathrm{~h}$ & 1.76 & Ferric reduction oxidase 7 \\
\hline
\end{tabular}

\section{Conclusions}

In this study, the birch transcriptome dataset was generated by high-throughput sequencing and uploaded to the NCBI SRA database. In addition, the dynamic changes of gene expression under low-temperature treatment were observed, and a large number of low-temperature response genes 
were discovered. These genes are connected with plant hormones, $\mathrm{Ca}^{2+}$ transduction pathways, phenylpropanoids, lipids, starch and sucrose, amino acids, photosynthesis, and enzymes related to the synthesis of protective metabolites. When studied we the changes in TFs under low-temperature stress, we observed that the contribution of AP2/ERF family genes was particularly prominent. Transcriptome and expression-level analysis of birch leaves provide valuable resources for the functional annotation of low-temperature-response genes.

Author Contributions: Conceptualization, S.C. (Su Chen); software, S.C. (Song Chen); validation, D.Z. and S.Y.; investigation, D.Z.; resources, S.C. (Su Chen); writing-original draft preparation, S.Y. and D.Z.; writing-review and editing, S.C. (Su Chen); supervision, S.C. (Su Chen); funding acquisition, S.C. (Su Chen). All authors have read and agreed to the published version of the manuscript.

Funding: This research was funded by the National Natural Science Foundation of China, grant number 31870659; the Fundamental Research Funds for the Central Universities, grant number 2572019CG08; Heilongjiang Touyan Innovation Team Program (Tree Genetics and Breeding Innovation Team); and the 111 Project (B16010).

Acknowledgments: We thank the reviewers and editors who provided constructive comments on our manuscript.

Conflicts of Interest: The authors declare no conflict of interest.

\section{Appendix A}

Table A1. The genes and primers used for qRT-PCR analysis.

\begin{tabular}{|c|c|c|}
\hline Gene & Primer & Primer Sequence \\
\hline $18 S$ RNA & 18S-R & GCAGGTTAGCGAAATGCGATAC \\
\hline $18 S$ RNA & 18S-F & GAGGTAGCTTCGGGCGCAACT \\
\hline Bpev01.c1851.g0002 & BP001R & CGAAGGTTGTTCCTATTGGAGGT \\
\hline Bpev01.c1851.g0002 & BP001F & САТСТССААТСТСААССТСТGТТСС \\
\hline Bpev01.c1851.g0001 & BP002R & CAGCTTCTTGTTGAGCCAATCTC \\
\hline Bpev01.c1851.g0001 & $\mathrm{BP} 002 \mathrm{~F}$ & GCGGTCTCTTCССTTGCTTAAATG \\
\hline Bpev01.c1189.g0015 & BP003R & GAGATCCTGTTGCCTTCCAGTAC \\
\hline Bpev01.c1189.g0015 & BP003F & AGCTTGATGGGAAGAGACCAG \\
\hline Bpev01.c1161.g0015 & BP004R & GTCGGTCGATTGCGAGGTTG \\
\hline Bpev01.c1161.g0015 & $\mathrm{BP} 004 \mathrm{~F}$ & GACCTCTGCATCCCACTCTG \\
\hline Bpev01.c1161.g0014 & BP005R & GTCGGTCGATTGCGAGGTTG \\
\hline Bpev01.c1161.g0014 & BP005F & GACСТCTGCATCССАСТСТСТG \\
\hline Bpev01.c0455.g0003 & BP006R & GCTGCCATGCTTCCTGTCTC \\
\hline Bреv01.c0455.g0003 & BP006F & ACTTCCGGGATTTCGTTTCCAC \\
\hline Bpev01.c0390.g0007 & BP007R & CTTTCCAATGGGCTTGTCCG \\
\hline Bреv01.c0390.g0007 & BP007F & CGGACGAGGAGTTGGTGAATC \\
\hline Bpev01.c0357.g0068 & BP008R & GCTTTCCAATACCCAGACACCG \\
\hline Bpev01.c0357.g0068 & BP008F & TCGATTCCACCCAACTGATGAG \\
\hline Bреv01.c0210.g0037 & BP009R & CCATTCGGGTACTTCCGGTC \\
\hline Bpev01.c0210.g0037 & BP009F & CCTGTGTTGTCGTTGGCTTC \\
\hline Bреv01.c0162.g0012 & BP010R & GTCTAGCTCCGTTCGGGTAC \\
\hline Bpev01.c0162.g0012 & BP010F & ACTTATCCACCGGCTTGAACC \\
\hline Bреv01.c0073.g0013 & BP011R & CTCTGAATATCCTTCGCCGTCCC \\
\hline Bpev01.c0073.g0013 & $\mathrm{BP} 011 \mathrm{~F}$ & CCGGGAGGACGAAGTTCAAG \\
\hline Bpev01.c0001.g0070 & BP012R & CAAGGCCAAAGATGCTTCAAGACAC \\
\hline Bреv01.c0001.g0070 & $\mathrm{BP} 012 \mathrm{~F}$ & TACTTGTCTCAAGATGCTCCTCTG \\
\hline Bpev01.c0001.g0069 & BP013R & CCTTGGTCGCCCTGTTAGTC \\
\hline Bpev01.c0001.g0069 & BP013F & GCAGGACAGGAGTGGGATAC \\
\hline Bреv01.c0000.g0209 & $\mathrm{BP} 014 \mathrm{R}$ & GTTGCTGTTGGAGTTGAATTTCGG \\
\hline Bpev01.c0000.g0209 & $\mathrm{BP} 014 \mathrm{~F}$ & ССТTTGCATCTTACССТTCTTGCTC \\
\hline
\end{tabular}


Table A2. Statistics of sequencing data.

\begin{tabular}{cccccccc}
\hline Sample & Raw Date & $\begin{array}{c}\text { Clean } \\
\text { Date }\end{array}$ & $\begin{array}{c}\text { Base } \\
\text { Number }\end{array}$ & Q20\% & Q30\% & $\begin{array}{c}\text { GC } \\
\text { Content } \\
\mathbf{1}\end{array}$ & $\begin{array}{c}\text { Mapped } \\
\text { Ratio }\end{array}$ \\
\hline CK_rep1 & $25,672,243$ & $25,670,448$ & $7.68 \mathrm{~Gb}$ & $97.63 \%$ & $93.76 \%$ & $47.07 \%$ & $96.07 \%$ \\
CK_rep2 & $28,604,148$ & $28,602,122$ & $8.56 \mathrm{~Gb}$ & $97.69 \%$ & $93.93 \%$ & $47.16 \%$ & $96.34 \%$ \\
1h_rep1 & $28,418,115$ & $22,838,434$ & $6.83 \mathrm{~Gb}$ & $97.77 \%$ & $94.08 \%$ & $47.14 \%$ & $96.64 \%$ \\
1h_rep2 & $27,638,049$ & $27,255,820$ & $8.16 \mathrm{~Gb}$ & $97.56 \%$ & $93.60 \%$ & $46.90 \%$ & $96.52 \%$ \\
1.5h_rep1 & $22,409,000$ & $23,396,121$ & $7.00 \mathrm{~Gb}$ & $97.68 \%$ & $93.92 \%$ & $47.33 \%$ & $96.42 \%$ \\
1.5h_rep2 & $23,397,739$ & $23,729,617$ & $7.10 \mathrm{~Gb}$ & $97.58 \%$ & $93.71 \%$ & $47.05 \%$ & $96.43 \%$ \\
1.5h_rep3 & $23,731,305$ & $24,169,972$ & $7.23 \mathrm{~Gb}$ & $97.64 \%$ & $93.82 \%$ & $46.63 \%$ & $96.46 \%$ \\
2h_rep1 & $24,171,686$ & $22,157,427$ & $6.63 \mathrm{~Gb}$ & $97.58 \%$ & $93.67 \%$ & $47.48 \%$ & $96.16 \%$ \\
2h_rep2 & $22,840,004$ & $23,331,820$ & $6.98 \mathrm{~Gb}$ & $97.65 \%$ & $93.85 \%$ & $47.10 \%$ & $96.29 \%$ \\
2.5h_rep1 & $27,257,640$ & $24,693,732$ & $7.39 \mathrm{~Gb}$ & $97.56 \%$ & $93.63 \%$ & $47.09 \%$ & $96.30 \%$ \\
2.5h_rep2 & $24,695,387$ & $24,822,662$ & $7.43 \mathrm{~Gb}$ & $97.76 \%$ & $94.02 \%$ & $48.47 \%$ & $96.33 \%$ \\
3h_rep1 & $24,824,310$ & $28,740,756$ & $8.60 \mathrm{~Gb}$ & $97.67 \%$ & $93.85 \%$ & $47.46 \%$ & $96.24 \%$ \\
3h_rep2 & $22,158,962$ & $27,162,399$ & $8.13 \mathrm{~Gb}$ & $97.90 \%$ & $94.35 \%$ & $47.73 \%$ & $96.47 \%$ \\
Average & $25,062,968$ & $25,120,872$ & $7.52 \mathrm{~Gb}$ & $97.50 \%$ & $93.60 \%$ & $47.28 \%$ & $96.36 \%$ \\
\hline
\end{tabular}

Table A3. Pathway enrichment analysis in DEGs ( $p$-value $\leq 0.05)$.

\begin{tabular}{|c|c|c|c|c|}
\hline Items & ID & DEGs & All & $p$-Value \\
\hline Metabolic pathways & ko01100 & 349 & 2246 & $6.39 \times 10^{-26}$ \\
\hline Biosynthesis of secondary metabolites & ko01110 & 210 & 1107 & $1.87 \times 10^{-24}$ \\
\hline Ribosome & ko03010 & 76 & 364 & $2.58 \times 10^{-11}$ \\
\hline Biosynthesis of amino acids & ko01230 & 46 & 251 & $4.57 \times 10^{-6}$ \\
\hline Carbon metabolism & ko01200 & 43 & 273 & 0.0002 \\
\hline Phenylpropanoid biosynthesis & ko00940 & 41 & 166 & $1.89 \times 10^{-8}$ \\
\hline Plant hormone signal transduction & ko04075 & 39 & 273 & 0.00195 \\
\hline Plant-pathogen interaction & ko04626 & 30 & 170 & 0.00034 \\
\hline Starch and sucrose metabolism & ko00500 & 30 & 165 & 0.000218 \\
\hline Cysteine and methionine metabolism & ko00270 & 23 & 121 & 0.00066 \\
\hline Glycolysis/gluconeogenesis & ko00010 & 23 & 116 & 0.000396 \\
\hline MAPK signaling pathway-plant & ko04016 & 21 & 134 & 0.00812 \\
\hline Amino sugar and nucleotide sugar metabolism & ko00520 & 18 & 131 & 0.0382 \\
\hline Pyruvate metabolism & ko00620 & 18 & 86 & 0.000949 \\
\hline Fatty acid metabolism & ko01212 & 18 & 69 & $9.62 \times 10^{-5}$ \\
\hline Purine metabolism & ko00230 & 17 & 100 & 0.00828 \\
\hline DNA replication & ko03030 & 14 & 50 & 0.000304 \\
\hline Valine, leucine, and isoleucine degradation & ko00280 & 13 & 51 & 0.00104 \\
\hline beta-Alanine metabolism & ko00410 & 13 & 50 & 0.000887 \\
\hline Flavonoid biosynthesis & ko00941 & 13 & 22 & $9.57 \times 10^{-7}$ \\
\hline Fructose and mannose metabolism & ko00051 & 12 & 64 & 0.0131 \\
\hline Glycerolipid metabolism & ko00561 & 12 & 60 & 0.00858 \\
\hline Fatty acid biosynthesis & ko00061 & 12 & 43 & 0.000823 \\
\hline Carbon fixation in photosynthetic organisms & ko00710 & 11 & 69 & 0.0426 \\
\hline Phenylalanine metabolism & ko00360 & 11 & 32 & 0.000316 \\
\hline $\begin{array}{l}\text { Phenylalanine, tyrosine and tryptophan } \\
\text { biosynthesis }\end{array}$ & ko00400 & 10 & 56 & 0.0289 \\
\hline Fatty acid degradation & ko00071 & 10 & 47 & 0.0111 \\
\hline Propanoate metabolism & ko00640 & 10 & 43 & 0.0066 \\
\hline Tyrosine metabolism & ko00350 & 9 & 40 & 0.0116 \\
\hline Pantothenate and CoA biosynthesis & ko00770 & 9 & 28 & 0.00161 \\
\hline
\end{tabular}


Table A3. Cont.

\begin{tabular}{ccccc}
\hline Items & ID & DEGs & All & $p$-Value \\
\hline alpha-Linolenic acid metabolism & ko00592 & 8 & 44 & 0.0442 \\
Carotenoid biosynthesis & ko00906 & 8 & 29 & 0.00627 \\
Sphingolipid metabolism & ko00600 & 8 & 27 & 0.00439 \\
Fatty acid elongation & ko00062 & 7 & 35 & 0.0398 \\
Lysine degradation & ko00310 & 7 & 34 & 0.0355 \\
Biotin metabolism & ko00780 & 7 & 16 & 0.0013 \\
ABC transporters & ko02010 & 6 & 26 & 0.0332 \\
Butanoate metabolism & ko00650 & 6 & 19 & 0.0103 \\
Lysine biosynthesis & ko00300 & 6 & 15 & 0.0041 \\
Other glycan degradation & ko00511 & 5 & 19 & 0.0334 \\
Riboflavin metabolism & ko00740 & 5 & 18 & 0.0282 \\
Biosynthesis of secondary & ko00999 & 5 & 12 & 0.00762 \\
metabolites-unclassified & ko00261 & 4 & 14 & 0.0449 \\
Monobactam biosynthesis & ko00603 & 4 & 9 & 0.0143 \\
Glycosphingolipid biosynthesis-globo and & ko00902 & 4 & 8 & 0.0105 \\
isoglobo series & ko00945 & 4 & 7 & 0.00746 \\
\hline Stilbenoterpenoid biosynthesis & & &
\end{tabular}

Table A4. DEGs were annotated for calcium signal pathway under low temperature stress in birch.

\begin{tabular}{|c|c|c|c|}
\hline Gene_ID & Time & $\log F C$ & Function \\
\hline Bpev01.c0480.g0081 & $2 \mathrm{~h}$ & 4.57 & Calmodulin-like, CML38 \\
\hline Bреv01.c1074.g0005 & $2.5 \mathrm{~h}$ & 4.66 & Calmodulin-like, CML25 \\
\hline Bpev01.c1074.g0006 & $3 \mathrm{~h}$ & 4.48 & Calcium-binding EF-hand family protein \\
\hline Bpev01.c1074.g0007 & $2.5 \mathrm{~h}$ & 3.94 & Calcium-binding EF-hand family protein \\
\hline Bpev01.c0147.g0007 & $1 \mathrm{~h}$ & 3.4 & $\begin{array}{l}\text { Calcium-dependent lipid-binding (CaLB domain) } \\
\text { family protein }\end{array}$ \\
\hline Bpev01.c0274.g0041 & $1 \mathrm{~h}$ & 3.6 & Calcium-binding EF-hand family protein \\
\hline Bpev01.c0445.g0003 & $1 \mathrm{~h}$ & 2.48 & $\begin{array}{l}\text { Calcium-dependent lipid-binding (CaLB domain) } \\
\text { family protein }\end{array}$ \\
\hline Bpev01.c0420.g0021 & $1 \mathrm{~h}$ & 2.43 & Calmodulin binding protein-like \\
\hline Bpev01.c0027.g0187 & $2.5 \mathrm{~h}$ & 2.94 & $\mathrm{Ca} 2^{+}$-dependent modulator of ICR1, CMI1 \\
\hline Bpev01.c0088.g0124 & $1 \mathrm{~h}$ & 3.79 & $\mathrm{Ca} 2^{+}$-dependent modulator of ICR1, CMI1 \\
\hline Bреv01.c2029.g0005 & $1 \mathrm{~h}$ & 3.38 & Calmodulin binding protein-like \\
\hline Bpev01.c0180.g0001 & $1 \mathrm{~h}$ & 3.08 & $\mathrm{Ca} 2^{+}$-dependent modulator of ICR1, CMI 1 \\
\hline Bpev01.c0281.g0075 & $2.5 \mathrm{~h}$ & 2.7 & Calmodulin-like, CML30 \\
\hline Bpev01.c0011.g0001 & $1 \mathrm{~h}$ & 2.52 & EF hand calcium-binding protein family \\
\hline Bpev01.c0328.g0033 & $1 \mathrm{~h}$ & 2.05 & Calmodulin-like, CML46 \\
\hline Bpev01.c0821.g0019 & $1 \mathrm{~h}$ & 1.96 & IQ calmodulin-binding motif family protein \\
\hline Bper01.c0145.g0021 & $1 \mathrm{~h}$ & 1.91 & $\begin{array}{l}\text { Calcium-dependent lipid-binding (CaLB domain) } \\
\text { family protein }\end{array}$ \\
\hline Bpev01.c0088.g0130 & $1 \mathrm{~h}$ & 2.96 & Calmodulin-like, CML30 \\
\hline Bреv01.c2409.g0002 & $1 \mathrm{~h}$ & 1.68 & Calcium-dependent protein kinase 1 \\
\hline Bpev01.c0511.g0002 & $1 \mathrm{~h}$ & 1.56 & CBL-interacting protein kinase 5 \\
\hline Bpev01.c0022.g0034 & $1 \mathrm{~h}$ & 1.54 & Calcium-dependent protein kinase 28 \\
\hline Bper01.c1700.g0004 & $1 \mathrm{~h}$ & 2.06 & Calcium-dependent protein kinase family protein \\
\hline Bpev01.c0159.g0009 & $1 \mathrm{~h}$ & 1.44 & $\begin{array}{l}\text { Copine (calcium-dependent phospholipid-binding } \\
\text { protein) family }\end{array}$ \\
\hline Bpev01.c0324.g0014 & $3 \mathrm{~h}$ & 1.49 & CBL-interacting protein kinase 7 \\
\hline Bpev01.c1519.g0006 & $1 \mathrm{~h}$ & 1.4 & Calmodulin binding protein-like \\
\hline Bpev01.c0052.g0090 & $1 \mathrm{~h}$ & 2.12 & $\begin{array}{l}\text { Calmodulin-binding transcription activator protein } \\
\text { with CG-1 and Ankyrin domains }\end{array}$ \\
\hline
\end{tabular}


Table A4. Cont.

\begin{tabular}{|c|c|c|c|}
\hline Gene_ID & Time & $\log F C$ & Function \\
\hline Bpev01.c0570.g0019 & $1 \mathrm{~h}$ & 1.37 & Calmodulin-like, CML30 \\
\hline Bpev01.c0318.g0004 & $3 \mathrm{~h}$ & 1.36 & Calmodulin-like, CML5 \\
\hline Bpev01.c0126.g0019 & $2.5 \mathrm{~h}$ & 1.55 & Calmodulin-like, CML5 \\
\hline Bpev01.c0029.g0091 & $1 \mathrm{~h}$ & 1.35 & Calcium-dependent protein kinase 19 \\
\hline Bpev01.c0044.g0059 & $1 \mathrm{~h}$ & 1.32 & CBL-interacting protein kinase 25 \\
\hline Bpev01.c0147.g0003 & $1 \mathrm{~h}$ & 1.9 & $\begin{array}{l}\text { Calcium-dependent lipid-binding (CaLB domain) } \\
\text { family protein }\end{array}$ \\
\hline Bpev01.c1106.g0007 & $3 \mathrm{~h}$ & 1.17 & CBL-interacting protein kinase 20 \\
\hline Bpev01.c2470.g0003 & $1 \mathrm{~h}$ & 1.17 & $\begin{array}{l}\text { Calcium-dependent lipid-binding (CaLB domain) } \\
\text { family protein }\end{array}$ \\
\hline Bpev01.c1002.g0005 & $1 \mathrm{~h}$ & 1.11 & $\begin{array}{c}\text { Calcium-dependent lipid-binding (CaLB domain) } \\
\text { family protein }\end{array}$ \\
\hline Bpev01.c0298.g0010 & $3 \mathrm{~h}$ & 1.4 & $\begin{array}{l}\text { Calcium-dependent lipid-binding (CaLB domain) } \\
\text { family protein }\end{array}$ \\
\hline Bpev01.c0763.g0002 & $2.5 \mathrm{~h}$ & 1.74 & Calmodulin-like, CML30 \\
\hline Bреv01.c0145.g0018 & $2.5 \mathrm{~h}$ & 1.97 & Calcium-binding EF-hand family protein \\
\hline Bpev01.c0022.g0125 & $1 \mathrm{~h}$ & 1.01 & $\begin{array}{l}\text { Calcium-dependent phosphotriesterase } \\
\text { superfamily protein }\end{array}$ \\
\hline Bpev01.c0036.g0009 & $1 \mathrm{~h}$ & 1 & Plant calmodulin-binding protein \\
\hline Bpev01.c0135.g0041 & $1 \mathrm{~h}$ & -1.1 & Calmodulin-binding protein \\
\hline Bpev01.c0523.g0005 & $1 \mathrm{~h}$ & -1.1 & $\begin{array}{l}\text { Calcium-dependent lipid-binding (CaLB domain) } \\
\text { plant phosphoribosyltransferase family protein }\end{array}$ \\
\hline Bpev01.c3512.g0001 & $1 \mathrm{~h}$ & -1.14 & Calcium-binding EF-hand family protein \\
\hline Bpev01.c1359.g0001 & $1 \mathrm{~h}$ & -1.38 & $\mathrm{Na}^{+} / \mathrm{Ca}^{2+}$ exchanger, NCL \\
\hline Bpev01.c2062.g0001 & $1 \mathrm{~h}$ & -1.44 & $\mathrm{Na}^{+} / \mathrm{Ca}^{2+}$ exchanger, NCL \\
\hline Bpev01.c2002.g0003 & $1 \mathrm{~h}$ & -1.71 & $\begin{array}{l}\text { C2 calcium/lipid-binding plant } \\
\text { phosphoribosyltransferase family protein }\end{array}$ \\
\hline Bpev01.c1295.g0001 & $1 \mathrm{~h}$ & -1.88 & $\begin{array}{l}\text { C2 calcium/lipid-binding plant } \\
\text { phosphoribosyltransferase family protein }\end{array}$ \\
\hline Bpev01.c2062.g0002 & $1 \mathrm{~h}$ & -1.94 & $\mathrm{Na}^{+} / \mathrm{Ca}^{2+}$ exchanger, NCL \\
\hline Bpev01.c0442.g0045 & $1 \mathrm{~h}$ & -1.99 & $\begin{array}{l}\text { C2 calcium/lipid-binding plant } \\
\text { phosphoribosyltransferase family protein }\end{array}$ \\
\hline Bpev01.c0127.g0096 & $2.5 \mathrm{~h}$ & -3.34 & Calmodulin binding protein \\
\hline
\end{tabular}

Table A5. Hormone-related DEGs under low temperature stress in birch.

\begin{tabular}{|c|c|c|c|}
\hline Gene_ID & Time & $\log F C$ & Function \\
\hline \multicolumn{4}{|c|}{$\mathrm{ABA}$} \\
\hline Bpev01.c0870.g0008 & $2.5 \mathrm{~h}$ & 4.01 & ABA 8 '-hydroxylase, polypeptide 1 \\
\hline Bpev01.c0352.g0006 & $1 \mathrm{~h}$ & 3.75 & Protein phosphatase $2 \mathrm{C}$ family protein \\
\hline Bpev01.c0294.g0006 & $2.5 \mathrm{~h}$ & 3.66 & Nine-cis-epoxycarotenoid dioxygenase 3 \\
\hline Bpev01.c0115.g0107 & $1 \mathrm{~h}$ & 3.92 & Protein phosphatase $2 \mathrm{C}$ family protein \\
\hline Bpev01.c0129.g0031 & $2.5 \mathrm{~h}$ & 2.04 & Protein phosphatase $2 \mathrm{C}$ family protein \\
\hline Bpev01.c1183.g0023 & $1 \mathrm{~h}$ & 1.9 & Protein phosphatase $2 \mathrm{C}$ family protein \\
\hline Bpev01.c0455.g0029 & $1 \mathrm{~h}$ & 1.81 & Protein phosphatase $2 \mathrm{C}$ family protein, $\mathrm{PP} 2 \mathrm{CG} 1$ \\
\hline Bpev01.c0015.g0093 & $3 \mathrm{~h}$ & 1.57 & Protein phosphatase $2 \mathrm{C}$ family protein, APD5 \\
\hline Bpev01.c0268.g0003 & $1 \mathrm{~h}$ & 2.42 & Nine-cis-epoxycarotenoid dioxygenase 4 \\
\hline Bpev01.c0279.g0011 & $3 \mathrm{~h}$ & 1.26 & Protein phosphatase $2 \mathrm{C}$ family protein, $\mathrm{AP} 2 \mathrm{C} 1$ \\
\hline Bpev01.c0015.g0010 & $1 \mathrm{~h}$ & 1.25 & ABA deficient 1, ABA1 \\
\hline Bpev01.c0500.g0004 & $1 \mathrm{~h}$ & 1.24 & Protein phosphatase $2 \mathrm{C}$ family protein \\
\hline Bpev01.c0265.g0015 & $1 \mathrm{~h}$ & 1.18 & Protein phosphatase $2 \mathrm{C}$ family protein, CIPP1 \\
\hline
\end{tabular}


Table A5. Cont.

\begin{tabular}{|c|c|c|c|}
\hline Gene_ID & Time & $\log \mathrm{FC}$ & Function \\
\hline Bpev01.c0280.g0015 & $2.5 \mathrm{~h}$ & 1.67 & Protein phosphatase $2 \mathrm{C}$ family protein \\
\hline Bpev01.c1081.g0001 & $1 \mathrm{~h}$ & 1.03 & Protein phosphatase $2 \mathrm{C}$ family protein \\
\hline Bpev01.c0298.g0028 & $1 \mathrm{~h}$ & -1.26 & Beta-hydroxylase 1 \\
\hline Bpev01.c0142.g0059 & $1 \mathrm{~h}$ & -1.4 & Protein phosphatase $2 \mathrm{C}$ family protein \\
\hline Bpev01.c0467.g0019 & $1 \mathrm{~h}$ & -1.61 & Protein phosphatase $2 \mathrm{C}$ family protein, PP2C.D3 \\
\hline Bpev01.c0328.g0025 & $2.5 \mathrm{~h}$ & -2.79 & ABA $8^{\prime}$-hydroxylase, polypeptide 4 \\
\hline Bpev01.c1475.g0010 & $3 \mathrm{~h}$ & -1.91 & Protein phosphatase $2 \mathrm{C}$ family protein, $\mathrm{PP} 2 \mathrm{C} 62$ \\
\hline Bpev01.c0245.g0042 & $1 \mathrm{~h}$ & -1.91 & ABA $8^{\prime}$-hydroxylase, polypeptide 2 \\
\hline Bpev01.c0038.g0101 & $1 \mathrm{~h}$ & -2.39 & Protein phosphatase $2 \mathrm{C}$ family protein \\
\hline Bpev01.c1272.g0023 & $2.5 \mathrm{~h}$ & -3.53 & ABA deficient $2, \mathrm{ABA} 2$ \\
\hline \multicolumn{4}{|c|}{ Ethylene } \\
\hline Bpev01.c1161.g0016 & $2.5 \mathrm{~h}$ & 5.23 & Ethylene responsive element binding factor 5 \\
\hline Bpev01.c1161.g0018 & $2.5 \mathrm{~h}$ & 3.67 & Ethylene responsive element binding factor 1 \\
\hline Bpev01.c1161.g0014 & $2.5 \mathrm{~h}$ & 4.63 & Ethylene responsive element binding factor 5 \\
\hline Bpev01.c1161.g0017 & $2.5 \mathrm{~h}$ & 3.12 & Ethylene responsive element binding factor 1 \\
\hline Bpev01.c1161.g0012 & $2.5 \mathrm{~h}$ & 4.68 & Ethylene responsive element binding factor 5 \\
\hline Bpev01.c1161.g0013 & $2.5 \mathrm{~h}$ & 4.62 & Ethylene responsive element binding factor 5 \\
\hline Bpev01.c0764.g0013 & $1 \mathrm{~h}$ & 2.86 & Ethylene response factor 1 \\
\hline Bpev01.c0343.g0032 & $1 \mathrm{~h}$ & 2.78 & Ethylene response factor 1 \\
\hline Bpev01.c1851.g0001 & $2.5 \mathrm{~h}$ & 3.7 & Ethylene responsive element binding factor 2 \\
\hline Bpev01.c1161.g0015 & $2.5 \mathrm{~h}$ & 4.43 & Ethylene responsive element binding factor 5 \\
\hline Bpev01.c0299.g0032 & $2.5 \mathrm{~h}$ & 1.95 & Ethylene-forming enzyme \\
\hline Bpev01.c0523.g0001 & $2.5 \mathrm{~h}$ & 1.41 & Ethylene-insensitive3-like 3 \\
\hline \multicolumn{4}{|c|}{ JA } \\
\hline Bpev01.c0052.g0052 & $2.5 \mathrm{~h}$ & -2.92 & Jasmonate-zim-domain protein 10, Jaz 10 \\
\hline Bpev01.c0136.g0009 & $1 \mathrm{~h}$ & -1.62 & N-MYC down-regulated-like 1 \\
\hline Bpev01.c0423.g0007 & $1 \mathrm{~h}$ & -1.98 & 4-coumarate: CoA ligase 3 \\
\hline Bpev01.c0161.g0057 & $2.5 \mathrm{~h}$ & -2.5 & Jasmonic acid carboxyl methyltransferase \\
\hline \multicolumn{4}{|c|}{ GA } \\
\hline Bpev01.c0118.g0033 & $2.5 \mathrm{~h}$ & 3.05 & Gibberellin 3-oxidase 1 \\
\hline Bpev01.c0094.g0034 & $1 \mathrm{~h}$ & -1.09 & Gibberellin-regulated family protein \\
\hline Bpev01.c1673.g0004 & $1 \mathrm{~h}$ & -1.25 & Gibberellin-regulated family protein \\
\hline Bpev01.c0411.g0004 & $1 \mathrm{~h}$ & -2.18 & Gibberellin-regulated family protein \\
\hline Bpev01.c1170.g0013 & $1 \mathrm{~h}$ & -5 & Gibberellin-regulated family protein \\
\hline \multicolumn{4}{|c|}{ SA } \\
\hline Bpev01.c0343.g0021 & $1 \mathrm{~h}$ & 7.67 & Pathogenesis-related gene 1 \\
\hline Bpev01.c0154.g0058 & $1 \mathrm{~h}$ & 2.58 & Pathogenesis-related thaumatin superfamily protein \\
\hline Bpev01.c1477.g0007 & $1 \mathrm{~h}$ & 1.97 & Pathogenesis-related family protein \\
\hline Bpev01.c0889.g0015 & $1 \mathrm{~h}$ & 1.46 & Pathogenesis-related thaumatin superfamily protein \\
\hline Bpev01.c0022.g0043 & $1 \mathrm{~h}$ & 1.89 & Pathogenesis-related thaumatin superfamily protein \\
\hline Bpev01.c0082.g0060 & $1 \mathrm{~h}$ & -2.32 & Pathogenesis-related thaumatin superfamily protein \\
\hline Bpev01.c1688.g0003 & $1.5 \mathrm{~h}$ & -2.26 & Pathogenesis-related family protein \\
\hline Bpev01.c1525.g0004 & $2.5 \mathrm{~h}$ & -2.88 & Pathogenesis-related thaumatin superfamily protein \\
\hline Bpev01.c0889.g0016 & $1 \mathrm{~h}$ & -2.42 & Pathogenesis-related thaumatin superfamily protein \\
\hline Bpev01.c1688.g0002 & $3 \mathrm{~h}$ & -3.46 & Pathogenesis-related family protein \\
\hline Bpev01.c0030.g0023 & $1 \mathrm{~h}$ & -2.64 & Pathogenesis-related thaumatin superfamily protein \\
\hline
\end{tabular}


Table A6. Starch and sucrose metabolism-related DEGs under low-temperature stress in birch.

\begin{tabular}{|c|c|c|c|}
\hline Gene_ID & Time & $\log F C$ & Function \\
\hline Bpev01.c0162.g0017 & $1 \mathrm{~h}$ & 5.07 & Beta-glucosidase 45 \\
\hline Bpev01.c0080.g0100 & $1 \mathrm{~h}$ & 4.58 & PfkB-like carbohydrate kinase family protein \\
\hline Bpev01.c0283.g0018 & $1 \mathrm{~h}$ & 3.15 & Beta-amylase 5 \\
\hline Bpev01.c0092.g0014 & $1 \mathrm{~h}$ & 2.77 & Beta glucosidase 41 \\
\hline Bреv01.c0275.g0002 & $1 \mathrm{~h}$ & 2.59 & Sucrose-phosphate synthase family protein \\
\hline Bpev01.c1949.g0001 & $1 \mathrm{~h}$ & 2.07 & Chloroplast beta-amylase \\
\hline Bpev01.c0000.g0208 & $1 \mathrm{~h}$ & 1.76 & $\begin{array}{c}\text { Haloacid dehalogenase-like hydrolase (HAD) } \\
\text { superfamily protein }\end{array}$ \\
\hline Bpev01.c0842.g0013 & $1 \mathrm{~h}$ & 1.54 & Trehalose-6-phosphate synthase \\
\hline Bpev01.c0053.g0012 & $1 \mathrm{~h}$ & 1.42 & Beta glucosidase 11 \\
\hline Bpev01.c0016.g0107 & $1 \mathrm{~h}$ & 1.58 & Sucrose phosphate synthase $3 \mathrm{~F}$ \\
\hline Bpev01.c0264.g0007 & $1 \mathrm{~h}$ & 1.26 & Glycosyl hydrolases family 31 protein \\
\hline Bреv01.c1918.g0005 & $1 \mathrm{~h}$ & 1.32 & Glycosyl hydrolase family protein \\
\hline Bpev01.c2037.g0001 & $3 \mathrm{~h}$ & 1.14 & $\begin{array}{c}\text { Haloacid dehalogenase-like hydrolase (HAD) } \\
\text { superfamily protein }\end{array}$ \\
\hline Bpev01.c0294.g0013 & $1 \mathrm{~h}$ & 1.19 & Sucrose synthase 3 \\
\hline Bpev01.c0478.g0015 & $1 \mathrm{~h}$ & 1.01 & Starch branching enzyme 2.2 \\
\hline Bpev01.c0727.g0009 & $1 \mathrm{~h}$ & -1.24 & Sucrose synthase 6 \\
\hline Bреv01.c0762.g0008 & $1 \mathrm{~h}$ & -1.29 & PfkB-like carbohydrate kinase family protein \\
\hline Bpev01.c0145.g0042 & $1 \mathrm{~h}$ & -1.95 & O-Glycosyl hydrolases family 17 protein \\
\hline Bpev01.c0051.g0185 & $1 \mathrm{~h}$ & -1.51 & Sucrose synthase 4 \\
\hline Bpev01.c0127.g0110 & $1 \mathrm{~h}$ & -1.53 & Beta-glucosidase 47 \\
\hline Bpev01.c2368.g0004 & $1 \mathrm{~h}$ & -1.57 & O-Glycosyl hydrolases family 17 protein \\
\hline Bpev01.c0141.g0019 & $1 \mathrm{~h}$ & -1.58 & Glycosyl hydrolase $9 \mathrm{C} 2$ \\
\hline Bpev01.c0263.g0003 & $1 \mathrm{~h}$ & -2.55 & O-Glycosyl hydrolases family 17 protein \\
\hline Bpev01.c0717.g0033 & $1 \mathrm{~h}$ & -1.77 & Nudix hydrolase homolog 14 \\
\hline Bpev01.c1136.g0002 & $1 \mathrm{~h}$ & -1.84 & Glycosyl hydrolase 9B18 \\
\hline Bpev01.c0127.g0064 & $1 \mathrm{~h}$ & -1.91 & O-Glycosyl hydrolases family 17 protein \\
\hline Bpev01.c1526.g0006 & $1 \mathrm{~h}$ & -2.06 & Glycosyl hydrolase 9B1 \\
\hline Bpev01.c1187.g0006 & $1 \mathrm{~h}$ & -2.68 & Glycosyl hydrolases family 32 protein \\
\hline Bpev01.c0470.g0030 & $2.5 \mathrm{~h}$ & -4.96 & Beta glucosidase 17 \\
\hline
\end{tabular}

Table A7. DEGs related to lipid metabolism pathway under low-temperature stress in birch.

\begin{tabular}{cccccc}
\hline Gene_ID & $\mathbf{1 ~ h}$ & $\mathbf{1 . 5} \mathbf{~ h}$ & $\mathbf{2} \mathbf{~ h}$ & $\mathbf{2 . 5} \mathbf{~ h}$ & $\mathbf{3 ~ h}$ \\
\hline Bpev01.c0552.g0011 & 8.94 & - & - & - & 8.66 \\
Bpev01.c0062.g0066 & 5.1 & - & - & - & - \\
Bpev01.c0870.g0008 & - & - & - & 4.01 & 3.62 \\
Bpev01.c0294.g0006 & - & - & - & 3.66 & 3.02 \\
Bpev01.c1114.g0003 & 3.53 & - & - & - & - \\
Bpev01.c1092.g0004 & 5.29 & 3.41 & - & 3.17 & 3.55 \\
Bpev01.c1153.g0001 & 3.32 & - & - & - & - \\
Bpev01.c0118.g0033 & - & - & - & 3.05 & - \\
Bpev01.c0517.g0001 & 2.94 & - & - & - & - \\
Bpev01.c0574.g0036 & 2.39 & - & - & - & - \\
Bpev01.c0094.g0036 & 2.77 & 2.19 & - & - & - \\
Bpev01.c1335.g0003 & 2.08 & - & - & - & - \\
Bpev01.c0940.g0001 & 3.97 & 1.97 & - & 3.03 & - \\
Bpev01.c0364.g0019 & 1.95 & - & - & - & - \\
Bpev01.c0050.g0029 & 2.82 & 1.86 & - & 1.83 & - \\
Bpev01.c0261.g0045 & 1.83 & - & - & - & - \\
Bpev01.c0020.g0005 & 1.72 & - & - & - & - \\
Bpev01.c1100.g0005 & - & - & - & 1.69 & - \\
Bpev01.c0374.g0017 & 1.64 & - & - & - & - \\
Bpev01.c0569.g0008 & 1.53 & - & - & 1.32 & 1.24 \\
\hline
\end{tabular}


Table A7. Cont.

\begin{tabular}{|c|c|c|c|c|c|}
\hline Gene_ID & $1 \mathrm{~h}$ & $1.5 \mathrm{~h}$ & $2 \mathrm{~h}$ & $2.5 \mathrm{~h}$ & $3 \mathrm{~h}$ \\
\hline Bреv01.c0901.g0021 & 1.99 & 1.48 & - & 2.03 & 1.41 \\
\hline Bреv01.c0015.g0012 & 1.41 & 1.42 & - & - & - \\
\hline Bреv01.c0480.g0025 & 1.4 & - & - & - & - \\
\hline Bpev01.c0841.g0011 & 1.34 & - & - & - & - \\
\hline Bреv01.c0401.g0013 & 1.33 & - & - & - & - \\
\hline Bреv01.c0063.g0018 & 1.29 & - & - & - & - \\
\hline Bреv01.c1135.g0005 & 1.26 & - & - & - & - \\
\hline Bpev01.c0015.g0010 & 1.25 & - & - & - & - \\
\hline Bреv01.c0018.g0112 & 1.22 & - & - & - & - \\
\hline Bреv01.c0275.g0035 & 1.81 & 1.21 & - & - & - \\
\hline Bpev01.c0473.g0025 & 1.1 & - & - & - & - \\
\hline Bреv01.c0190.g0079 & 1.04 & - & - & - & - \\
\hline Bреv01.c1060.g0006 & -1 & - & - & - & - \\
\hline Bреv01.c0575.g0024 & -1.01 & - & - & - & - \\
\hline Bреv01.c0038.g0134 & -1.03 & - & - & - & - \\
\hline Bpev01.c1828.g0001 & -1.04 & - & - & - & - \\
\hline Bреv01.c0850.g0003 & -2.16 & -1.04 & - & - & - \\
\hline Вреv01.c0821.g0002 & -1.04 & - & - & - & - \\
\hline Bреv01.c0892.g0002 & -1.06 & - & - & - & - \\
\hline Bреv01.c0496.g0022 & -1.08 & - & - & - & - \\
\hline Bреv01.c0147.g0001 & -1.96 & -1.09 & - & -2.91 & -2 \\
\hline Bреv01.c0052.g0167 & -1.11 & - & - & - & - \\
\hline Bpev01.c0717.g0003 & -1.19 & -1.11 & - & - & - \\
\hline Bреv01.c0425.g0035 & -1.19 & -1.16 & - & -1.55 & - \\
\hline Bpev01.c0038.g0045 & -1.43 & -1.17 & - & - & - \\
\hline Bpev01.c0854.g0013 & -1.22 & - & - & - & - \\
\hline Bреv01.c0555.g0007 & -1.25 & - & - & - & - \\
\hline Bреv01.c0166.g0013 & -1.26 & - & - & - & - \\
\hline Вреv01.c0298.g0028 & -1.26 & - & - & - & - \\
\hline Bреv01.c0027.g0082 & -1.26 & - & - & - & - \\
\hline Bреv01.c2636.g0002 & -1.29 & - & - & - & - \\
\hline Bpev01.c0652.g0023 & -1.31 & - & - & - & - \\
\hline Bpev01.c0449.g0049 & -1.33 & - & - & - & - \\
\hline Bpev01.c1534.g0010 & -2.15 & -1.34 & - & - & -1.38 \\
\hline Bpev01.c1475.g0006 & -2.23 & -1.36 & - & - & - \\
\hline Вреv01.c0045.g0058 & -1.37 & - & - & - & - \\
\hline Bреv01.c1170.g0009 & -1.39 & - & - & - & - \\
\hline Bреv01.c0506.g0024 & -2.39 & -1.43 & - & - & - \\
\hline Bpev01.c1484.g0012 & - & -1.44 & - & - & - \\
\hline Bpev01.c0645.g0001 & -1.44 & - & - & - & - \\
\hline Вреv01.c0275.g0066 & -1.44 & - & - & - & - \\
\hline Bрет01.c0842.g0018 & -1.5 & - & - & - & - \\
\hline Bреv01.c0163.g0009 & -1.78 & -1.52 & - & -1.43 & - \\
\hline Bреv01.c0052.g0192 & -1.53 & - & - & - & - \\
\hline Bреv01.c0531.g0014 & -1.54 & - & - & - & - \\
\hline Bpev01.c1714.g0001 & -1.54 & - & - & - & - \\
\hline Bpev01.c0327.g0073 & -1.55 & - & - & - & - \\
\hline Bреv01.c1382.g0026 & -1.58 & - & - & - & - \\
\hline Bpev01.c1080.g0002 & -1.52 & -1.58 & - & -1.79 & - \\
\hline Bреv01.c0458.g0015 & -2.9 & -1.6 & - & - & - \\
\hline Bреv01.c0190.g0038 & -1.6 & - & - & - & - \\
\hline Bреv01.c0114.g0058 & -2.25 & -1.64 & - & -1.76 & - \\
\hline
\end{tabular}


Table A7. Cont.

\begin{tabular}{|c|c|c|c|c|c|}
\hline Gene_ID & $1 \mathrm{~h}$ & $1.5 \mathrm{~h}$ & $2 \mathrm{~h}$ & $2.5 \mathrm{~h}$ & $3 \mathrm{~h}$ \\
\hline Bpev01.c0052.g0046 & -1.67 & - & - & - & - \\
\hline Bpev01.c0213.g0061 & - & -1.67 & - & - & - \\
\hline Bpev01.c1044.g0004 & -1.68 & - & - & - & - \\
\hline Bреv01.c0135.g0028 & -1.69 & - & - & - & - \\
\hline Bреv01.c1627.g0007 & -2.7 & -1.73 & - & -3.79 & - \\
\hline Bреv01.c0052.g0017 & -1.78 & - & - & - & - \\
\hline Bpev01.c0237.g0054 & -1.8 & - & - & - & - \\
\hline Вреv01.c0169.g0048 & -2.9 & -1.81 & - & - & - \\
\hline Bреv01.c1414.g0002 & -2.4 & -1.82 & - & - & - \\
\hline Bреv01.c1006.g0017 & -1.88 & - & - & - & - \\
\hline Bреv01.c0473.g0007 & -1.9 & - & - & - & - \\
\hline Bреv01.c0245.g0042 & -1.91 & - & - & - & - \\
\hline Bpev01.c0253.g0008 & -1.95 & - & - & - & - \\
\hline Bpev01.c0027.g0080 & -2.11 & - & - & - & - \\
\hline Bреv01.c0053.g0009 & -2.12 & - & - & - & - \\
\hline Bреv01.c1312.g0005 & -2.53 & -2.15 & - & - & - \\
\hline Bpev01.c0523.g0003 & -2.2 & - & - & - & - \\
\hline Bреv01.c2716.g0001 & -2.28 & - & - & -3.31 & - \\
\hline Bpev01.c0000.g0055 & -2.49 & -2.28 & - & -2.21 & -1.75 \\
\hline Bpev01.c0457.g0037 & -2.3 & - & - & - & - \\
\hline Bpev01.c0680.g0004 & -2.33 & - & - & - & - \\
\hline Bреv01.c0224.g0002 & -2.49 & - & - & - & -1.19 \\
\hline Вреv01.c0161.g0057 & - & - & - & -2.5 & - \\
\hline Bреv01.c0038.g0153 & -2.26 & -2.56 & - & - & - \\
\hline Bреv01.c1529.g0009 & -2.64 & - & - & - & - \\
\hline Bpev01.c1272.g0023 & -2.8 & - & - & -3.53 & - \\
\hline Вреv01.c0275.g0067 & -2.82 & - & - & - & - \\
\hline Bpev01.c1836.g0006 & -2.87 & - & - & - & - \\
\hline Bреv01.c0939.g0009 & -3.05 & - & - & - & - \\
\hline Bреv01.c0046.g0006 & -2.76 & -3.16 & -1.95 & -3.68 & - \\
\hline Bреv01.c0217.g0001 & -3.17 & - & - & -2.85 & - \\
\hline Bреv01.c1574.g0002 & -3.49 & - & - & -6.21 & - \\
\hline Bреv01.c0312.g0012 & - & - & - & -3.66 & - \\
\hline Bреv01.c0261.g0078 & - & -3.81 & - & -5.58 & - \\
\hline Вреv01.c0565.g0007 & - & -3.92 & - & -4.55 & - \\
\hline Bреv01.c0594.g0020 & - & - & - & -4.92 & - \\
\hline Bреv01.c0227.g0002 & -2.41 & -8.16 & - & -4.96 & - \\
\hline
\end{tabular}

Table A8. Amino acids biosynthesis-related DEGs under low-temperature stress in birch.

\begin{tabular}{cccc}
\hline Gene_ID & Time & logFC & Funchtion \\
\hline Bpev01.c0015.g0143 & $1 \mathrm{~h}$ & 9.63 & N-acetyl-1-glutamate synthase 2 \\
Bpev01.c0112.g0007 & $3 \mathrm{~h}$ & 8.44 & Pyridoxal-5' -phosphate-dependent enzyme family protein \\
Bpev01.c0511.g0007 & $3 \mathrm{~h}$ & 7.44 & Aldolase superfamily protein \\
Bpev01.c0115.g0053 & $1 \mathrm{~h}$ & 4.03 & Aldolase superfamily protein \\
Bpev01.c0274.g0001 & $1 \mathrm{~h}$ & 2.69 & ATP phosphoribosyl transferase 2 \\
Bpev01.c0148.g0010 & $1 \mathrm{~h}$ & 4.59 & Branched-chain amino acid transaminase 2 \\
Bpev01.c0462.g0003 & $1 \mathrm{~h}$ & 2.08 & 3-deoxy-d-arabino-heptulosonate 7-phosphate synthase \\
Bpev01.c0082.g0091 & $2.5 \mathrm{~h}$ & 2.37 & HOPW1-1-interacting 1 \\
Bpev01.c0083.g0021 & $1 \mathrm{~h}$ & 1.85 & Phosphofructokinase 2 \\
Bpev01.c0137.g0017 & $1 \mathrm{~h}$ & 2.58 & Cysteine synthase D1 \\
Bpev01.c0425.g0050 & $1 \mathrm{~h}$ & 1.31 & Aldolase superfamily protein \\
Bpev01.c2707.g0004 & $1 \mathrm{~h}$ & 1.26 & Cytosolic NADP ${ }^{+}$-dependent isocitrate dehydrogenase \\
\hline
\end{tabular}


Table A8. Cont.

\begin{tabular}{|c|c|c|c|}
\hline Gene_ID & Time & $\log F C$ & Funchtion \\
\hline Bpev01.c0929.g0016 & $1 \mathrm{~h}$ & 1.2 & O-acetylserine (thiol) lyase (OAS-TL) isoform A1 \\
\hline Bреv01.c0146.g0019 & $1 \mathrm{~h}$ & 1.16 & $\begin{array}{c}\text { D-aminoacid aminotransferase-like PLP-dependent } \\
\text { enzymes superfamily protein }\end{array}$ \\
\hline Bpev01.c0145.g0054 & $1 \mathrm{~h}$ & 1.57 & Glutamine synthase clone R1 \\
\hline Bpev01.c0517.g0019 & $1 \mathrm{~h}$ & 1.04 & D-ribulose-5-phosphate-3-epimerase \\
\hline Bpev01.c0112.g0020 & $1 \mathrm{~h}$ & 1 & Serine acetyltransferase $2 ; 2$ \\
\hline Bpev01.c0000.g0226 & $1.5 \mathrm{~h}$ & -1.02 & Aspartate aminotransferase \\
\hline Bреv01.c0198.g0001 & $1 \mathrm{~h}$ & -1.59 & Enolase 1 \\
\hline Bpev01.c0169.g0035 & $1 \mathrm{~h}$ & -1.1 & Pyruvate kinase family protein \\
\hline Bреv01.c0192.g0016 & $1 \mathrm{~h}$ & -1.24 & Arginase \\
\hline Bpev01.c1518.g0002 & $1 \mathrm{~h}$ & -1.12 & Ketol-acid reductoisomerase \\
\hline Bреv01.c0120.g0017 & $1 \mathrm{~h}$ & -1.12 & D-3-phosphoglycerate dehydrogenase \\
\hline Bpev01.c0874.g0032 & $1 \mathrm{~h}$ & -1.13 & Dihydrodipicolinate synthase \\
\hline Bpev01.c0146.g0013 & $1 \mathrm{~h}$ & -1.14 & $\begin{array}{l}\text { Pyridoxal phosphate (PLP)-dependent transferases } \\
\text { superfamily protein }\end{array}$ \\
\hline Bpev01.c2230.g0005 & $1 \mathrm{~h}$ & -1.15 & Pyruvate kinase family protein \\
\hline Bpev01.c0192.g0009 & $1 \mathrm{~h}$ & -1.24 & $\begin{array}{c}\text { RNA 3'-terminal phosphate cyclase/enolpyruvate } \\
\text { transferase, alpha/beta }\end{array}$ \\
\hline Bpev01.c1356.g0002 & $1 \mathrm{~h}$ & -1.28 & $\begin{array}{l}\text { Dehydroquinate dehydratase, putative / shikimate } \\
\text { dehydrogenase, putative }\end{array}$ \\
\hline Bpev01.c2160.g0012 & $2.5 \mathrm{~h}$ & -1.31 & Glyceraldehyde-3-phosphate dehydrogenase of plastid 2 \\
\hline Bpev01.c1534.g0010 & $1 \mathrm{~h}$ & -2.15 & Plastidic pyruvate kinase beta subunit 1 \\
\hline Bреv01.c0275.g0025 & $1 \mathrm{~h}$ & -1.35 & Aspartate kinase-homoserine dehydrogenase ii \\
\hline Bpev01.c0683.g0005 & $1 \mathrm{~h}$ & -1.49 & Methionine adenosyltransferase 3 \\
\hline Bpev01.c1040.g0016 & $1 \mathrm{~h}$ & -1.5 & Glyceraldehyde-3-phosphate dehydrogenase C2 \\
\hline Bpev01.c1115.g0006 & $1 \mathrm{~h}$ & -1.78 & Pyridoxal-5'-phosphate-dependent enzyme family protein \\
\hline Bpev01.c0000.g0150 & $1 \mathrm{~h}$ & -2.03 & 3-deoxy-D-arabino-heptulosonate 7-phosphate synthase 1 \\
\hline Bpev01.c0449.g0055 & $1 \mathrm{~h}$ & -1.83 & Semialdehyde dehydrogenase family protein \\
\hline Bpev01.c3196.g0001 & $1 \mathrm{~h}$ & -2.32 & Dihydrodipicolinate reductase \\
\hline Bреv01.c0652.g0026 & $1 \mathrm{~h}$ & -2.34 & Shikimate kinase 1 \\
\hline Bpev01.c0279.g0010 & $1 \mathrm{~h}$ & -2.53 & Glutamine-dependent asparagine synthase 1 \\
\hline Bpev01.c0167.g0024 & $1.5 \mathrm{~h}$ & -2.65 & Tyrosine transaminase family protein \\
\hline
\end{tabular}

Table A9. Photosynthesis-related DEGs under low-temperature stress in birch.

\begin{tabular}{cccc}
\hline Gene_ID & Time & logFC & Function \\
\hline Bpev01.c0154.g0066 & $1.5 \mathrm{~h}$ & 4.19 & Ferretin 1 \\
Bpev01.c1891.g0002 & $1.5 \mathrm{~h}$ & 4.02 & Photosystem II reaction center protein A \\
Bpev01.c1891.g0006 & $1.5 \mathrm{~h}$ & 3.49 & Photosystem II reaction center protein C \\
Bpev01.c1891.g0007 & $1.5 \mathrm{~h}$ & 3.05 & Photosystem I, PsaA/PsaB protein \\
Bpev01.c1286.g0001 & $2.5 \mathrm{~h}$ & 1.7 & Phosphoenolpyruvate carboxykinase 1 \\
Bpev01.c0088.g0023 & $1 \mathrm{~h}$ & 1.43 & STT7 homolog STN7 \\
Bpev01.c0299.g0030 & $1 \mathrm{~h}$ & 1.37 & Fibrillin \\
Bpev01.c0245.g0079 & $1 \mathrm{~h}$ & 1.76 & Ferric reduction oxidase 7 \\
Bpev01.c1657.g0013 & $1 \mathrm{~h}$ & 1.16 & J-domain protein required for chloroplast accumulation \\
Bpev01.c0088.g0011 & $1 \mathrm{~h}$ & 1.46 & response 1 \\
Bpev01.c1275.g0002 & $1 \mathrm{~h}$ & 1.05 & Hydroxyproline-rich glycoprotein family protein \\
Bpev01.c0062.g0077 & $1 \mathrm{~h}$ & 1.04 & Photosystem II subunit R \\
Bpev01.c0038.g0100 & $1 \mathrm{~h}$ & 1.01 & DegP protease 1 \\
Bpev01.c0536.g0012 & $1.5 \mathrm{~h}$ & -1.05 & Chloroplast sensor kinase \\
Bpev01.c0142.g0012 & $1 \mathrm{~h}$ & -1.14 & Ferredoxin 3 \\
\hline
\end{tabular}


Table A9. Cont.

\begin{tabular}{cccc}
\hline Gene_ID & Time & logFC & Function \\
\hline Bpev01.c0118.g0021 & $1 \mathrm{~h}$ & -1.23 & $\begin{array}{c}\text { Mog1/PsbP/DUF1795-like photosystem II reaction center } \\
\text { PsbP family protein }\end{array}$ \\
Bpev01.c0005.g0002 & $1 \mathrm{~h}$ & -1.24 & Translocon at the outer envelope membrane of \\
chloroplasts 75-III \\
Bpev01.c1024.g0015 & $1 \mathrm{~h}$ & -1.34 & S-adenosylmethionine carrier 1 \\
Bpev01.c0298.g0026 & $1 \mathrm{~h}$ & -1.39 & Septum site-determining protein (MIND) \\
Bpev01.c0327.g0054 & $1 \mathrm{~h}$ & -1.52 & Tubulin/FtsZ family protein \\
Bpev01.c0615.g0010 & $1 \mathrm{~h}$ & -2.68 & Chlorophyll A-B binding family protein \\
\hline
\end{tabular}

Table A10. Differentially expressed TFs under different low-temperature stress time points.

\begin{tabular}{ccccccc}
\hline TF Family & Total & $\mathbf{1} \mathbf{h}$ & $\mathbf{1 . 5} \mathbf{h}$ & $\mathbf{2} \mathbf{h}$ & $\mathbf{2 . 5} \mathbf{h}$ & $\mathbf{3} \mathbf{h}$ \\
\hline C2H2 & 58 & 53 & 11 & 6 & 16 & 14 \\
AP2-EREBP & 42 & 29 & 25 & 14 & 24 & $\mathbf{2 4}$ \\
MYB-HB-like & 27 & 21 & 7 & 0 & 7 & 6 \\
NAM & 20 & 18 & 5 & 0 & 6 & 3 \\
WD40-like & 20 & 16 & 5 & 0 & 4 & 0 \\
WRKY & 16 & 15 & 2 & 0 & 5 & 5 \\
bHLH & 15 & 12 & 1 & 0 & 2 & 1 \\
Hap3/NF-YB & 15 & 1 & 13 & 0 & 10 & 0 \\
PHD & 14 & 10 & 2 & 1 & 0 & 0 \\
Homobox-WOX & 10 & 10 & 3 & 0 & 1 & 2 \\
bZIP & 8 & 8 & 0 & 0 & 0 & 0 \\
GRAS & 8 & 7 & 4 & 0 & 5 & 3 \\
Znf-B & 7 & 5 & 6 & 0 & 4 & 4 \\
C2C2-Dof & 6 & 4 & 1 & 0 & 2 & 2 \\
C2C2-GATA & 6 & 4 & 1 & 0 & 2 & 2 \\
BTB-POZ & 5 & 4 & 1 & 0 & 2 & 0 \\
C3H & 5 & 4 & 2 & 1 & 3 & 2 \\
C3H-WRC/GRF & 5 & 2 & 3 & 0 & 3 & 0 \\
HSF-type-DNA-binding & 5 & 4 & 3 & 0 & 3 & 2 \\
A20-like & 4 & 4 & 1 & 0 & 2 & 0 \\
HD-ZIP & 4 & 2 & 2 & 0 & 2 & 1 \\
\hline
\end{tabular}




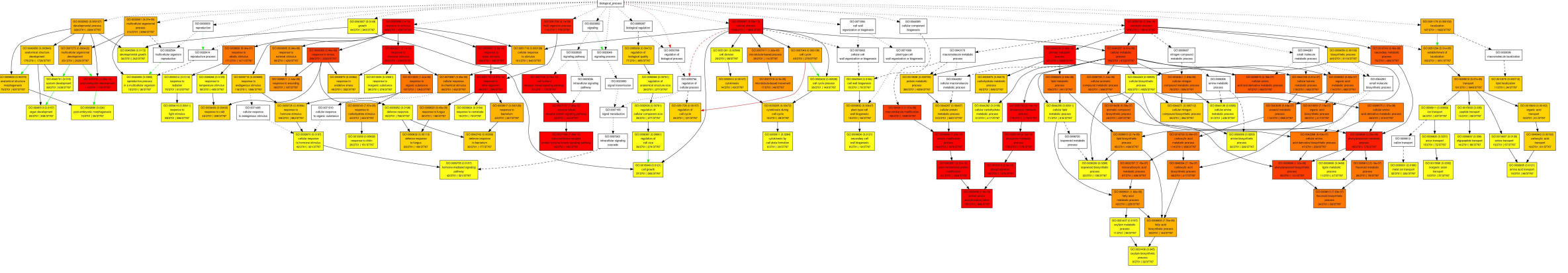

Figure A1. Biological process pathway. 


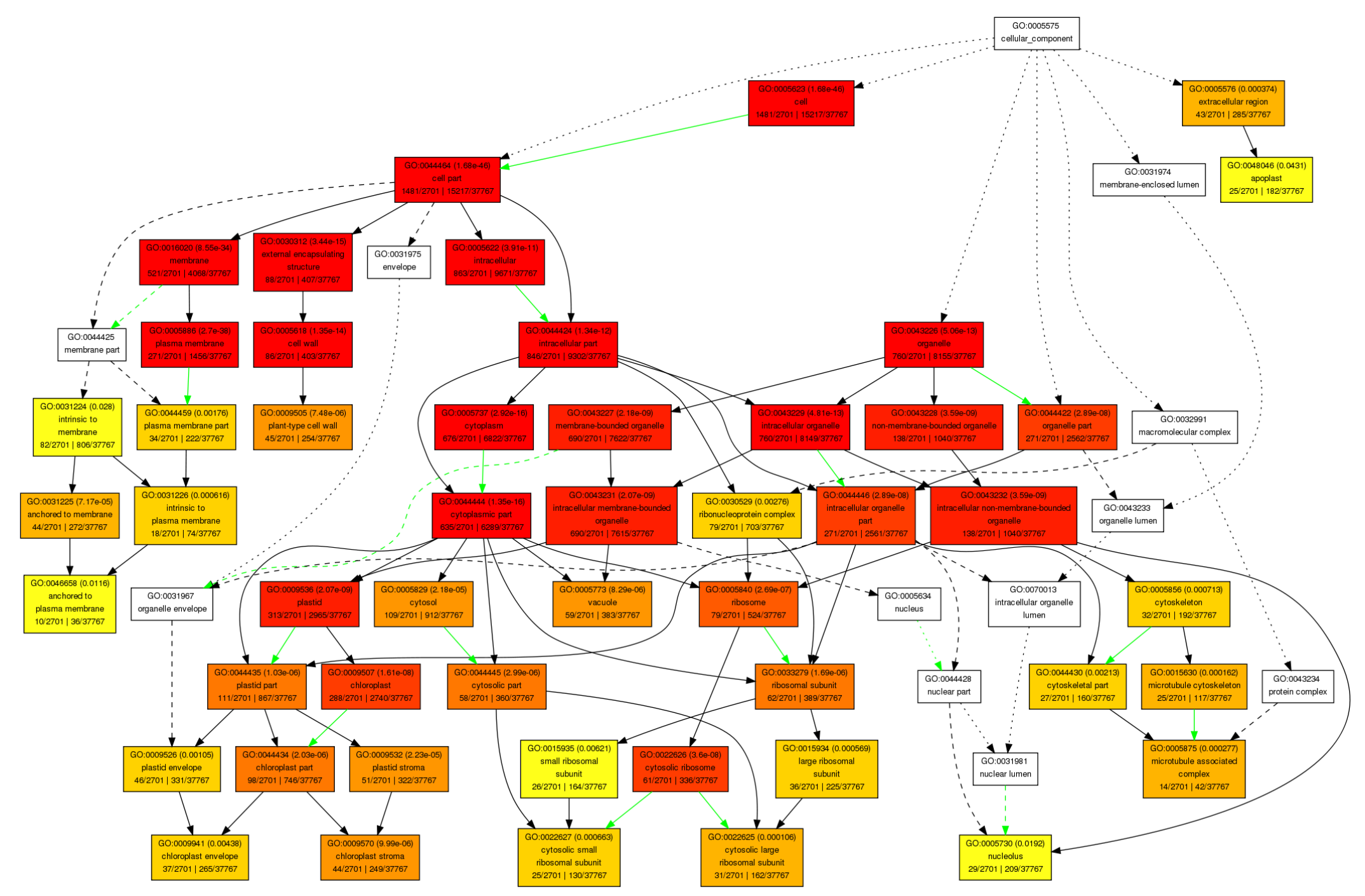

Figure A2. Cellular component pathway. 


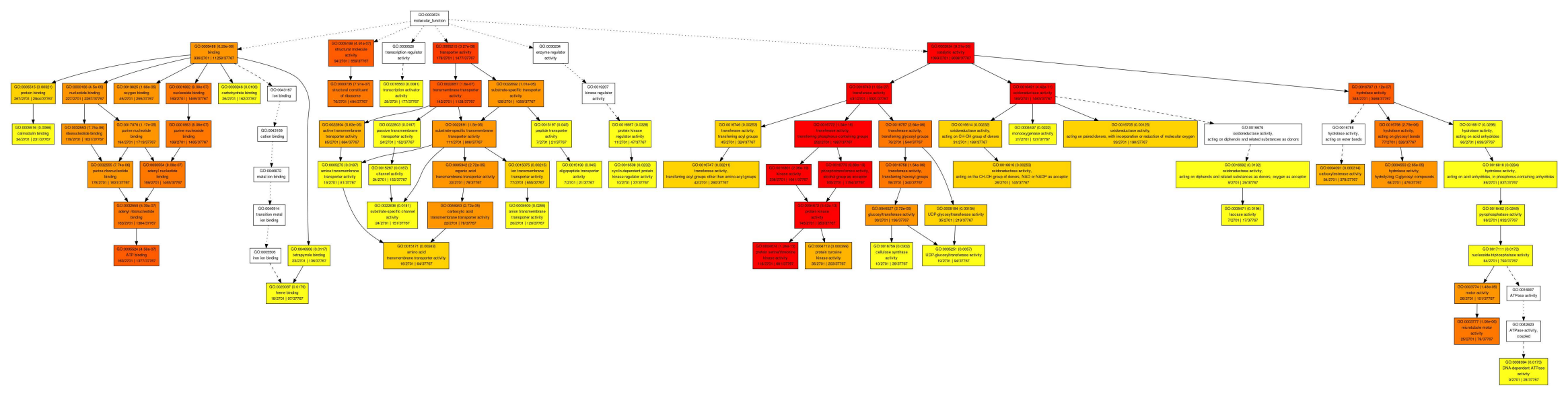

Figure A3. Molecular function pathway. 


\section{References}

1. Thomashow, M.F. PLANT COLD ACCLIMATION: Freezing Tolerance Genes and Regulatory Mechanisms. Annu. Rev. Plant Boil. 1999, 50, 571-599. [CrossRef]

2. Wang, X.; Zhao, Q.; Ma, C.-L.; Zhang, Z.H.; Cao, H.-L.; Kong, Y.-M.; Yue, C.; Hao, X.-Y.; Chen, L.; Ma, J.-Q.; et al. Global transcriptome profiles of Camellia sinensis during cold acclimation. BMC Genom. 2013, 14, 1-15. [CrossRef]

3. Mittler, R. Oxidative stress, antioxidants and stress tolerance. Trends Plant Sci. 2002, 7, 405-410. [CrossRef]

4. Uemura, M.; Yoshida, S. Studies on Freezing Injury in Plant Cells. Plant Physiol. 1986, 80, 187-195. [CrossRef]

5. Dodd, A.N.; Jakobsen, M.K.; Baker, A.J.; Telzerow, A.; Hou, S.-W.; Laplaze, L.; Barrot, L.; Poethig, R.S.; Haseloff, J.; Webb, A.A. Time of day modulates low-temperature Ca2+signals in Arabidopsis. Plant J. 2006, 48, 962-973. [CrossRef]

6. Qi, J.; Song, C.P.; Wang, B.; Zhou, J.; Kangasjärvi, J.; Zhu, J.K.; Gong, Z. Reactive oxygen species signaling and stomatal movement in plant responses to drought stress and pathogen attack J. J. Integr. Plant Biol. 2018, 60, 805-826. [CrossRef]

7. Mathur, S.; Agrawal, D.; Jajoo, A. Photosynthesis: Response to high temperature stress. J. Photochem. Photobiol. B Boil. 2014, 137, 116-126. [CrossRef]

8. Wu, G.; Xianlong, T.; Deguang, Y.; Crops, X.J.J. Research Progress on Physiology of Plant Cold Hardiness. Crops 2008, 3, S311.

9. Jeong, S.W.; Choi, S.M.; Lee, D.S.; Ahn, S.N.; Hur, Y.; Chow, W.S.; Park, Y.-I. Differential susceptibility of photosynthesis to light-chilling stress in rice (Oryza sativa L.) depends on the capacity for photochemical dissipation of light. Mol. Cells 2002, 13, 419-428.

10. Jan, W.; András, O.; Ravi, A.; Wu, C.J.N.A.R. The C-Terminal Region of Drosophila Heat Shock Factor (HSF) Contains a Constitutively Functional Transactivation Domain. Nucl. Acids Res. 1996, 24, 367-374.

11. Krause, E.; Dathe, M.; Wieprecht, T.; Bienert, M. Noncovalent immobilized artificial membrane chromatography, an improved method for describing peptide-lipid bilayer interactions. J. Chromatogr. A 1999, 849, 125-133. [CrossRef]

12. Medina, J.; Catala, R.; Salinas, J. The CBFs: Three arabidopsis transcription factors to cold acclimate. Plant Sci. 2011, 180, 3-11. [CrossRef]

13. Nakashima, K.; Ito, Y.; Yamaguchi-Shinozaki, K. Transcriptional Regulatory Networks in Response to Abiotic Stresses in Arabidopsis and Grasses. Plant Physiol. 2009, 149, 88-95. [CrossRef]

14. Zhu, J.K.; Chinnusamy, V.; Ohta, M.; Kanrar, S.; Lee, B.H.; Agarwal, M. ICE1, a regulator of cold induced transcriptome and freezing tolerance in plants. Genes Dev. 2003, 17, 1043-1054.

15. Zhu, J.K.; Agarwal, M.; Kapoor, A. Snow1: Interacts with Ice1 and regulates CBF expression and freezing tolerance in Arabidopsis. U.S. Patent No. 7,378,573, 27 May 2008.

16. Agarwal, M.; Hao, Y.; Kapoor, A.; Dong, C.-H.; Fujii, H.; Zheng, X.; Zhu, J.-K. A R2R3 Type MYB Transcription Factor Is Involved in the Cold Regulation of CBF Genes and in Acquired Freezing Tolerance. J. Boil. Chem. 2006, 281, 37636-37645. [CrossRef]

17. Shi, Y.; Tian, S.; Hou, L.; Huang, X.; Zhang, X.; Guo, H.; Yang, S. Ethylene Signaling Negatively Regulates Freezing Tolerance by Repressing Expression of CBF and Type-A ARR Genes in Arabidopsis. Plant Cell 2012, 24, 2578-2595. [CrossRef]

18. Sharma, R.; Singh, G.; Bhattacharya, S.; Singh, A. Comparative transcriptome meta-analysis of Arabidopsis thaliana under drought and cold stress. PLoS ONE 2018, 13, e203266. [CrossRef]

19. Yun, M.; Dai, X.; Xu, Y.; Wei, L.; Zheng, X.; Zeng, D.; Pan, Y.; Lin, X.; Liu, H.; Zhang, D.J.C. COLD1 confers chilling tolerance in rice. Cell 2015, 6, 1209-1221.

20. Gu, H.; Hagberg, P.; Zhou, W. Cold pretreatment enhances microspore embryogenesis in oilseed rape (Brassica napus L.). Plant Growth Regul. 2004, 42, 137-143. [CrossRef]

21. Ito, Y.; Katsura, K.; Maruyama, K.; Taji, T.; Kobayashi, M.; Seki, M. Functional analysis of rice dreb1/cbf-type transcription factors involved in cold-responsive gene expression in transgenic rice. Plant Cell Physiol. 2006, 47, 141-153. [CrossRef]

22. Winfield, M.O.; Lu, C.; Wilson, I.D.; Coghill, J.A.; Edwards, K.J. Plant responses to cold: Transcriptome analysis of wheat. Plant Biotechnol. J. 2010, 8, 749-771. [CrossRef] [PubMed] 
23. Lu, J.; Du, Z.-X.; Kong, J.; Chen, L.-N.; Qiu, Y.-H.; Li, G.-F.; Meng, X.-H.; Zhu, S.-F. Transcriptome Analysis of Nicotiana tabacum Infected by Cucumber mosaic virus during Systemic Symptom Development. PLoS ONE 2012, 7, e43447. [CrossRef]

24. Hu, H.; You, J.; Fang, Y.; Zhu, X.; Qi, Z.; Xiong, L.J.P.M.B. Erratum to: Characterization of transcription factor geneSNAC2conferring cold and salt tolerance in rice. Plant Mol. Biol. 2010, 72, 567-568. [CrossRef]

25. Huang, G.-T.; Ma, S.-L.; Bai, L.-P.; Zhang, L.; Ma, H.; Jia, P.; Liu, J.; Zhong, M.; Guo, Z.-F. Signal transduction during cold, salt, and drought stresses in plants. Mol. Boil. Rep. 2011, 39, 969-987. [CrossRef] [PubMed]

26. Kurepin, L.V.; Dahal, K.P.; Savitch, L.V.; Singh, J.; Bode, R.; Ivanov, A.G.; Hurry, V.M.; Hüner, N.P.A. Role of CBFs as Integrators of Chloroplast Redox, Phytochrome and Plant Hormone Signaling during Cold Acclimation. Int. J. Mol. Sci. 2013, 14, 12729-12763. [CrossRef]

27. Dong, C.-J.; Li, L.; Cao, N.; Shang, Q.M.; Zhang, Z.-G. Roles of phenylalanine ammonia-lyase in low temperature tolerance in cucumber seedlings. Chin. J. Appl. Ecol. 2015, 26, 2041-2049.

28. Savitch, L.V.; Harney, T.; Hüner, N.P.A. Sucrose metabolism in spring and winter wheat in response to high irradiance, cold stress and cold acclimation. Physiol. Plant. 2000, 108, 270-278. [CrossRef]

29. Christenhusz, M.J.; Byng, J.W. The number of known plants species in the world and its annual increase. Phytotaxa 2016, 261, 201. [CrossRef]

30. Doyle, J. CTAB Total DNA Isolation. Mol. Tech. Taxon. 1991, 57, $283-293$.

31. Chen, S.; Zhou, Y.; Chen, Y.; Gu, J. Fastp: An ultra-fast all-in-one FASTQ preprocessor. Bioinformatrics 2018, 34, i884-i890. [CrossRef]

32. Salojärvi, J.; Smolander, O.-P.; Nieminen, K.; Rajaraman, S.; Safronov, O.; Safdari, P.; Lamminmaki, A.; Immanen, J.; Lan, T.; Tanskanen, J.; et al. Genome sequencing and population genomic analyses provide insights into the adaptive landscape of silver birch. Nat. Genet. 2017, 49, 904-912. [CrossRef] [PubMed]

33. Kim, D.; Langmead, B.; Salzberg, S.L. HISAT: A fast spliced aligner with low memory requirements. Nat. Methods 2015, 12, 357-360. [CrossRef] [PubMed]

34. Rau, A.; Gallopin, M.; Celeux, G.; Jaffrézic, F. Data-based filtering for replicated high-throughput transcriptome sequencing experiments. Bioinformatrics 2013, 29, 2146-2152. [CrossRef]

35. Robinson, M.D.; McCarthy, D.J.; Smyth, G.K. edgeR: A Bioconductor package for differential expression analysis of digital gene expression data. Bioinformatrics 2009, 26, 139-140. [CrossRef] [PubMed]

36. Xie, C.; Mao, X.; Huang, J.; Ding, Y.; Wu, J.; Dong, S.; Kong, L.; Gao, G.; Li, C.; Wei, L. KOBAS 2.0: A web server for annotation and identification of enriched pathways and diseases. Nucleic Acids Res. 2011, 39, W316-W322. [CrossRef]

37. Altschul, S.F.; Madden, T.L.; Schäffer, A.A.; Zhang, J.; Zhang, Z.; Miller, W.; Lipman, D.J. Gapped BLAST and PSI-BLAST: A new generation of protein database search programs. Nucleic Acids Res. 1997, 25, 3389-3402. [CrossRef]

38. Pruitt, K.D.; Tatusova, T.; Maglott, N.R. NCBI Reference Sequence (RefSeq): A curated non-redundant sequence database of genomes, transcripts and proteins. Nucleic Acids Res. 2004, 33, D501-D504. [CrossRef]

39. Amos, B.; Rolf, A. The SWISS-PROT protein sequence data bank and its supplement TrEMBL in 1999. Nucleic Acids Res. 1999, 27, 49-54.

40. Minoru, K.; Susumu, G. KEGG: Kyoto Encyclopedia of Genes and Genomes. Nucleic Acids Res. 2000, 28, 27-30.

41. Chen, J.; Xia, X.; Yin, W. A poplar DRE-binding protein gene, PeDREB2L, is involved in regulation of defense response against abiotic stress. Gene 2011, 483, 36-42. [CrossRef]

42. Dai, Z.; Sheridan, J.M.; Gearing, L.J.; Moore, D.L.; Su, S.; Wormald, S.; Wilcox, S.; O'Connor, L.; Dickins, R.A.; Blewitt, M.E.; et al. edgeR: A versatile tool for the analysis of shRNA-seq and CRISPR-Cas9 genetic screens. F1000Research 2014, 3. [CrossRef] [PubMed]

43. Huang, L.M.; Lai, C.P.; Chen, L.F.O.; Chan, M.T.; Shaw, J.F. Arabidopsis SFAR4 is a novel GDSL-type esterase involved in fatty acid degradation and glucose tolerance. Bot. Stud. 2015, 56, 33. [CrossRef] [PubMed]

44. Valmonte, G.R.; Arthur, K.; Higgins, C.M.; MacDiarmid, R.M. Calcium-Dependent Protein Kinases in Plants: Evolution, Expression and Function. Plant Cell Physiol. 2014, 55, 551-569. [CrossRef]

45. Ma, W.; Berkowitz, G.A. $\mathrm{Ca}^{2+}$ conduction by plant cyclic nucleotide gated channels and associated signaling components in pathogen defense signal transduction cascades. New Phytol. 2010, 190, 566-572. [CrossRef]

46. Huang, C.; Ding, S.; Zhang, H.; Du, H.; An, L. CIPK7 is involved in cold response by interacting with CBL1 in Arabidopsis thaliana. Plant Sci. 2011, 181, 57-64. [CrossRef] [PubMed] 
47. Fu, J.; Miao, Y.; Shao, L.; Hu, T.; Yang, P. De novo transcriptome sequencing and gene expression profiling of Elymus nutans under cold stress. BMC Genom. 2016, 17, 1-19. [CrossRef]

48. Chen, C.; Zhang, Y.; Xu, Z.; Luan, A.; Mao, Q.; Feng, J.; Xie, T.; Gong, X.; Wang, X.; Chen, H.; et al. Transcriptome Profiling of the Pineapple under Low Temperature to Facilitate Its Breeding for Cold Tolerance. PLOS ONE 2016, 11, e163315. [CrossRef]

49. Wang, Z.; Gerstein, M.; Snyder, M. RNA-Seq: A revolutionary tool for transcriptomics. Nat. Rev. Genet. 2009, 10, 57-63. [CrossRef]

50. Rivero, R.M.; Ruiz, J.M.; García, P.C.; Lopez-Lefebre, L.R.; Sánchez, E.; Romero, L. Resistance to cold and heat stress: Accumulation of phenolic compounds in tomato and watermelon plants. Plant Sci. 2001, 160, 315-321. [CrossRef]

51. Michalak, A. Phenolic Compounds and Their Antioxidant Activity in Plants Growing under Heavy Metal Stress. J. Environ. Stud. 2006, 15, 523-530.

52. Asada, M.; Nishimura, T.; Ifuku, K.; Mino, H. Location of the extrinsic subunit PsbP in photosystem II studied by pulsed electron-electron double resonance. Biochim. Biophys. Acta (BBA) Bioenerg. 2018, 1859, 394-399. [CrossRef] [PubMed]

53. Abeynayake, S.W.; Etzerodt, T.P.; Jonavičienè, K.; Byrne, S.; Asp, T.; Boelt, B. Fructan metabolism and changes in fructan composition during cold acclimation in perennial ryegrass. J. Front. Plant Sci. 2015, 6, 329. [CrossRef] [PubMed]

54. Li, H.-W.; Zang, B.-S.; Deng, X.-W.; Wang, X.-P. Overexpression of the trehalose-6-phosphate synthase gene OsTPS1 enhances abiotic stress tolerance in rice. Planta 2011, 234, 1007-1018. [CrossRef] [PubMed]

55. Dionne, J.; Rochefort, S.; Huff, D.R.; Desjardins, Y.; Bertrand, A.; Castonguay, Y. Variability for Freezing Tolerance among 42 Ecotypes of Green-Type Annual Bluegrass. Crop. Sci. 2010, 50, 321-336. [CrossRef]

56. Chen, S.; Lin, X.; Zhang, D.; Li, Q.; Zhao, X.; Chen, S. Genome-Wide Analysis of NAC Gene Family in Betula pendula. Forests 2019, 10, 741. [CrossRef]

57. Ritonga, F.N.; Chen, S. Physiological and Molecular Mechanism Involved in Cold Stress Tolerance in Plants. Plants 2020, 9, 560. [CrossRef]

58. Wang, F.; Chen, S.; Liang, D.; Qu, G.-Z.; Chen, S.; Zhao, X.-Y. Transcriptomic analyses of Pinus koraiensis under different cold stresses. BMC Genom. 2020, 21, 10-14. [CrossRef]

59. Caspy, I.; Nelson, N. Structure of the plant photosystem I. Biochem. Soc. Trans. 2018, 46, 285-294. [CrossRef]

60. Pyke, K. The genetic control of plastid division in higher plants. Am. J. Bot. 1997, 84, 1017-1027. [CrossRef]

61. Ishikita, H.; Stehlik, D.; Golbeck, J.H.; Knapp, E.-W. Electrostatic Influence of PsaC Protein Binding to the PsaA/PsaB Heterodimer in Photosystem I. Biophys. J. 2005, 90, 1081-1089. [CrossRef] 